\title{
Machine learning and a computational fluid dynamic approach to estimate phase composition of chemical vapor deposition boron carbide
}

\section{Q.F. Zeng ( $\square$ qfzeng@nwpu.edu.cn )}

Northwestern Polytechnical University

\section{Yong Gao}

Northwestern Polytechnical University School of Materials Science and Engineering

\section{Kang Guan}

South China University of Technology

Jiantao Liu

Southwest Jiaotong University

\section{Zhiqiang Feng}

Southwest Jiaotong University

\section{Research Article}

Keywords: machine learning, computational fluid dynamic, chemical vapor deposition, boron carbide, B/C ratio, kinetic mechanisms

Posted Date: January 7th, 2021

DOI: https://doi.org/10.21203/rs.3.rs-56697/v2

License: (1) This work is licensed under a Creative Commons Attribution 4.0 International License. Read Full License 


\title{
Machine learning and a computational fluid dynamic approach to estimate phase composition of chemical vapor deposition boron carbide
}

Qingfeng Zeng ${ }^{\mathrm{a}, \mathrm{e}^{*}}$, Yong Gao ${ }^{\mathrm{a}}$, Kang Guan ${ }^{\mathrm{b} *}$, Jiantao Liu $^{\mathrm{c}}$, Zhiqiang Feng ${ }^{\mathrm{c}, \mathrm{d}}$

${ }^{a}$ Science and Technology on Thermostructural Composite Materials Laboratory, School of Materials Science and Engineering, Northwestern Polytechnical University, Xi'an 710072, China

${ }^{\mathrm{b}}$ School of Materials Science and Engineering, South China University of Technology, Guangzhou 510640, China

${ }^{\mathrm{c}}$ School of Mechanical Engineering, Southwest Jiaotong University, Chengdu, China

${ }^{\mathrm{d}}$ Evry University, Paris, France

${ }^{\mathrm{e}}$ MSEA International Institute for Materials Genome, Gu'an 065500, Hebei, China

* Corresponding author. E-mail address: qfzeng@nwpu.edu.cn (Q. Zeng).

* Corresponding author. E-mail address: mskguan@scut.edu.cn (K. Guan).

\begin{abstract}
Chemical vapor deposition is an important method for the preparation of boron carbide. Knowledge of the correlation between the phase composition of the deposit and the deposition conditions (temperature, inlet gas composition, total pressure, reactor configuration, and total flow rate) has not been completely determined. In this work, a novel approach to identify the kinetic mechanisms for the deposit composition is presented. Machine leaning (ML) and computational fluid dynamic (CFD) techniques are utilized to identify core factors that influence the deposit composition. It has been shown that ML, combined with $\mathrm{CFD}$, can reduce the prediction error from $25 \%$ to $7 \%$, compared with the ML approach alone. The sensitivity coefficient study shows that $\mathrm{BHCl}_{2}$ and $\mathrm{BCl}_{3}$ produce the most boron atoms, while $\mathrm{C}_{2} \mathrm{H}_{4}$ and $\mathrm{CH}_{4}$ are the main sources of carbon atoms. The new approach can accurately predict the deposited boron-carbon ratio and provide a new design solution for other multi-element systems.
\end{abstract}


Key words: machine learning; computational fluid dynamic; chemical vapor deposition; boron carbide; $\mathrm{B} / \mathrm{C}$ ratio; kinetic mechanisms

\section{Introduction}

Ceramic matrix composites (CMC) are ideal high-temperature materials because of their high-temperature resistance, wear resistance, low thermal conductivity, low thermal expansion coefficient, high chemical resistance, and high strength $[1,2]$. The common material systems of CMC are carbon fiber-reinforced silicon carbide ceramic matrix composite ,carbon fiber-reinforced carbon ceramic matrix composite and silicon carbide fiber-reinforced silicon carbide ceramic matrix composite $\left(\mathrm{C}_{\mathrm{f}} / \mathrm{SiC}, \mathrm{Cf}_{\mathrm{f}} / \mathrm{C}\right.$ and $\left.\mathrm{SiC}_{\mathrm{f}} / \mathrm{SiC}\right)[3,4]$. Because boron carbide $\left(\mathrm{B}_{\mathrm{x}} \mathrm{C}\right)$ can react with oxygen to generate boron oxide glass phase $\left(\mathrm{B}_{2} \mathrm{O}_{3}, \mathrm{HBO}_{3}\right.$ and $\left.\mathrm{H}_{3} \mathrm{BO}_{3}\right)$ and then seal cracks to prevent further oxidation [5-9], it is a good candidate for oxidation protective materials, and it is usually added to modify the interface and matrix of CMC.

Chemical vapor deposition (CVD) is a promising method for the preparation of boron carbide [7, 10-12]. The deposition mechanism for $\mathrm{B}_{\mathrm{x}} \mathrm{C}$ from a $\mathrm{BCl}_{3}-\mathrm{CH}_{4}-\mathrm{H}_{2}$ system has been previously studied. For instance, Berjonneau et al. identified the main gaseous species in situ by FTIR spectrometry as $\mathrm{BCl}_{3}, \mathrm{BHCl}_{2}$, and $\mathrm{HCl}[13,14]$. The $\mathrm{B} / \mathrm{C}$ ratio of the deposits decreased from 3.6 to 2 when the deposition temperature increased from $900{ }^{\circ} \mathrm{C}$ to $1100{ }^{\circ} \mathrm{C}$. Karaman et al. considered $\mathrm{BHCl}_{2}$ a by-product of the gas phase [11, 12]. Liu et al. systematically studied the relationship between deposition morphology and processing conditions [15]. They found that temperature has an effect on the phase composition and microstructure. At higher temperature $\left(1050{ }^{\circ} \mathrm{C}-1100{ }^{\circ} \mathrm{C}\right.$ ), the deposit consisted of two interlaced phases (PyC and boron carbide) with low boron content ranging from about 40-49 at.\%. At lower temperature $\left(900{ }^{\circ} \mathrm{C}-950{ }^{\circ} \mathrm{C}\right)$, layered and dense $\mathrm{B} 4 \mathrm{C}$ was produced with uniform phase 
composition, and its boron content is $65-79$ at.\%.

It was considered that $\mathrm{B}_{\mathrm{x}} \mathrm{C}$ exists as a single stable phase in a large homogeneous region from about 8 to 20 at.\% carbon concentration (the corresponding $\mathrm{B} / \mathrm{C}$ ratio is from 11.5 to 4) [7], and then a carbon-rich $\mathrm{B}_{\mathrm{x}} \mathrm{C}$ coating was obtained when $\mathrm{B} / \mathrm{C}$ ratio was lower than $4[15,16]$. Thus, it is important to elucidate the correlation between the $\mathrm{B} / \mathrm{C}$ ratio of the deposit and the deposition conditions to achieve reproducibility and consistency in the process. Apart from experimental studies, some numerical studies have provided an in-depth understanding of deposition kinetics [17-19], but scarce modeling attempts have been reported in boron carbide. The only paper was reported by Reinisch et al. [20], who combined experimental and reaction kinetics computations, and brought strong evidences of the presence of Methydichloroborane (MDB, $\mathrm{BCl}_{2} \mathrm{CH}_{3}$ ) in the process.

This paper is concerned with the correlation between deposit composition and processing parameters, such as temperature, inlet gas concentration, pressure, and gas flow velocity. A novel approach that considers gas phase kinetics and heat and mass transfer, in combination with machine learning (ML), is proposed to better understand the actual deposition mechanism and design of the deposit composition. The approach was applied to a $\mathrm{BCl}_{3}-\mathrm{CH}_{4}-\mathrm{H}_{2}$ system, which provides a useful foundation in understanding other precursor systems, such as $\mathrm{SiCl}_{4}-\mathrm{BCl}_{3}-\mathrm{NH}_{3}-\mathrm{H}_{2}-\mathrm{Ar}[21]$ and $\mathrm{BCl}_{3}-$ MTS-H2 [13].

This paper is organized as follows: In the second section, the details of the reactor model (RM) and two machine learning methods (ML), including error back propagation algorithm (BP) and support vector machine (SVM), are presented. In the third section, ML was used to directly correlate the global processing parameters (temperature, inlet gas composition, total pressure, reactor inner diameter, and total flow rate) with the experimentally measured boron-carbon ratio of the deposits. However, no satisfactory functional relationship was found. Then, the proposed method was applied and validated by comparing the experimental data. 


\section{Model simulation and prediction}

\subsection{Reactor-scale model (RM)}

The experimental data reported by Liu and Berjonneau are adopted in this study [13-15]. The specific deposition parameters for their experiments are listed in Table 1. In Liu's experiments, $\mathrm{B}_{4} \mathrm{C}$ and pyrolytic carbon $(\mathrm{PyC})$ were deposited onto graphite slices $(30 \mathrm{~mm} \times 15 \mathrm{~mm} \times 2 \mathrm{~mm})$ [15]. Boron trichloride $\left(\mathrm{BCl}_{3} \geq 99.99 \mathrm{vol} . \%\right)$ and methane $\left(\mathrm{CH}_{4} \geq 99.95\right.$ vol.\%) were used as the boron and carbon sources, respectively. The reactor was a vertical, hot-wall deposition furnace with a $200 \mathrm{~mm}$ inner diameter (a diagram of the equipment is shown in Figure 1). The temperature within the reactor was $900{ }^{\circ} \mathrm{C}-1100{ }^{\circ} \mathrm{C}$, and the pressure was fixed at $10 \mathrm{kPa}$. Berjonneau et al. adopted the analogous CVD reactor, which was a vertical silica glass tube $(700 \mathrm{~mm}$ length and $34 \mathrm{~mm}$ internal diameter) heated in its central part by a radio-frequency induction furnace. Their processing conditions are as follows: $850{ }^{\circ} \mathrm{C}-1000{ }^{\circ} \mathrm{C}, 2-12 \mathrm{kPa}$, and total flow rate of $210-390 \mathrm{sccm}$.

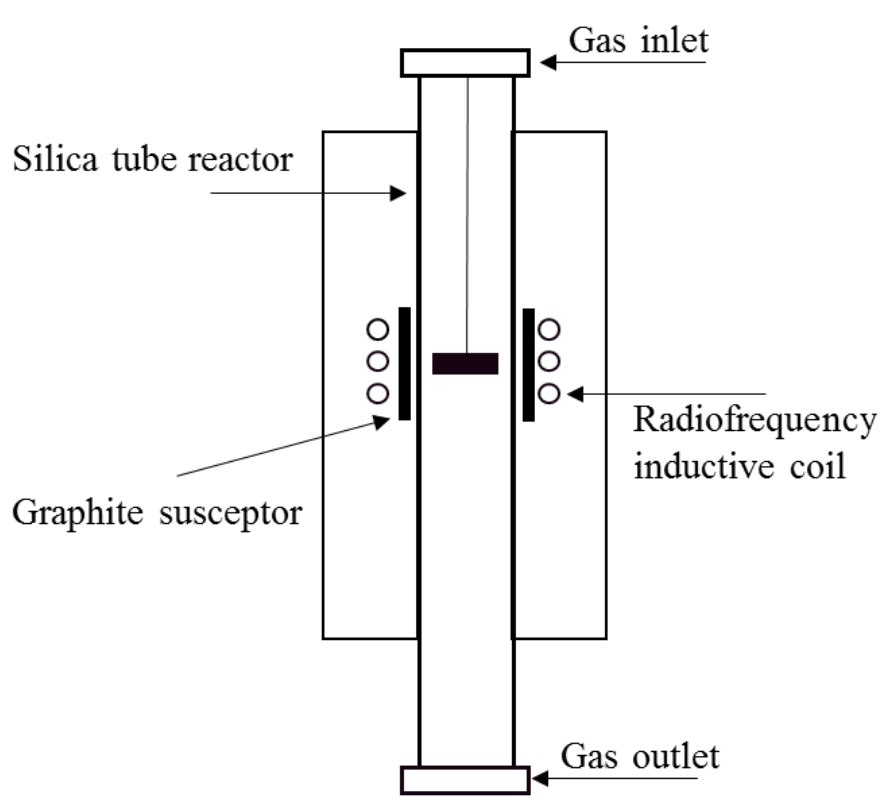

Fig 1. CVD reactor equipment diagram.

Table 1. CVD experimental conditions from references [13-15] 


\begin{tabular}{|c|c|c|c|c|c|c|c|c|}
\hline Number & $\mathbf{T} /{ }^{\circ} \mathbf{C}$ & $\mathrm{Q} / \mathrm{sccm}$ & ID/mm & $\mathbf{P} / \mathbf{k P a}$ & In_BCl 3 & In_CH & $\mathbf{I n} \_\mathbf{H}_{2}$ & $\mathrm{~B} / \mathrm{C}$ \\
\hline 1 & 900 & 125 & 200 & 10 & $10 / 23$ & $2 / 23$ & $11 / 23$ & 4.34 \\
\hline 2 & 900 & 125 & 200 & 10 & $2 / 19$ & $2 / 19$ & $15 / 19$ & 0.31 \\
\hline 3 & 900 & 125 & 200 & 10 & $2 / 5$ & $2 / 15$ & $11 / 15$ & 4.70 \\
\hline 4 & 950 & 125 & 200 & 10 & $8 / 23$ & $2 / 23$ & $13 / 23$ & 2.31 \\
\hline 5 & 950 & 125 & 200 & 10 & $4 / 15$ & $2 / 15$ & $9 / 15$ & 1.83 \\
\hline 6 & 950 & 125 & 200 & 10 & $8 / 21$ & $2 / 21$ & $11 / 21$ & 0.99 \\
\hline 7 & 1000 & 125 & 200 & 10 & $2 / 11$ & $2 / 11$ & $7 / 11$ & 0.35 \\
\hline 8 & 1000 & 125 & 200 & 10 & $4 / 19$ & $2 / 19$ & $13 / 19$ & 0.42 \\
\hline 9 & 1000 & 125 & 200 & 10 & $10 / 27$ & $2 / 27$ & $15 / 27$ & 2.32 \\
\hline 10 & 1050 & 125 & 200 & 10 & $6 / 17$ & $2 / 17$ & $9 / 17$ & 0.91 \\
\hline 11 & 1050 & 125 & 200 & 10 & $4 / 19$ & $2 / 19$ & $13 / 19$ & 0.70 \\
\hline 12 & 1050 & 125 & 200 & 10 & $8 / 19$ & $2 / 19$ & $9 / 19$ & 0.84 \\
\hline 13 & 1100 & 125 & 200 & 10 & $6 / 23$ & $2 / 23$ & $15 / 23$ & 0.78 \\
\hline 14 & 1100 & 125 & 200 & 10 & $10 / 19$ & $2 / 19$ & $7 / 19$ & 0.98 \\
\hline 15 & 1100 & 125 & 200 & 10 & $2 / 15$ & $2 / 15$ & $11 / 15$ & 0.44 \\
\hline 16 & 850 & 250 & 34 & 12 & $4 / 25$ & $1 / 25$ & $20 / 25$ & 3.5 \\
\hline 17 & 900 & 250 & 34 & 12 & $4 / 25$ & $1 / 25$ & $20 / 25$ & 2.8 \\
\hline 18 & 950 & 250 & 34 & 12 & $4 / 25$ & $1 / 25$ & $20 / 25$ & 2.8 \\
\hline 19 & 850 & 390 & 34 & 12 & $2 / 13$ & $1 / 13$ & $10 / 13$ & 3.6 \\
\hline 20 & 900 & 390 & 34 & 12 & $2 / 13$ & $1 / 13$ & $10 / 13$ & 3.0 \\
\hline 21 & 950 & 390 & 34 & 12 & $2 / 13$ & $1 / 13$ & $10 / 13$ & 3.2 \\
\hline
\end{tabular}




\begin{tabular}{lllllllll}
\hline $\mathbf{2 2}$ & 1000 & 390 & 34 & 12 & $2 / 13$ & $1 / 13$ & $10 / 13$ & 2.0 \\
$\mathbf{2 3}$ & 850 & 390 & 34 & 12 & $4 / 13$ & $1 / 13$ & $8 / 13$ & 2.9 \\
$\mathbf{2 4}$ & 900 & 390 & 34 & 12 & $4 / 13$ & $1 / 13$ & $8 / 13$ & 3.1 \\
$\mathbf{2 5}$ & 950 & 390 & 34 & 12 & $4 / 13$ & $1 / 13$ & $8 / 13$ & 2.6 \\
$\mathbf{2 6}$ & 850 & 210 & 34 & 12 & $2 / 7$ & $1 / 7$ & $4 / 7$ & 2.4 \\
$\mathbf{2 7}$ & 900 & 210 & 34 & 12 & $2 / 7$ & $1 / 7$ & $4 / 7$ & 2.3 \\
$\mathbf{2 8}$ & 950 & 210 & 34 & 12 & $2 / 7$ & $1 / 7$ & $4 / 7$ & 2.9 \\
\hline
\end{tabular}

Here, $\mathrm{T}$ is deposition temperature, and $\mathrm{Q}$ is total flow rate. $\mathrm{In}_{-} \mathrm{BCl}_{3}$, $\mathrm{In}_{-} \mathrm{CH}_{4}$ and $\mathrm{In}_{-} \mathrm{H}_{2}$ are the input molar fraction of $\mathrm{BCl}_{3}, \mathrm{CH}_{4}$, and $\mathrm{H}_{2}$, respectively. ID is reactor inner diameter, $\mathrm{P}$ is the total pressure, and $\mathrm{B} / \mathrm{C}$ is the boron-carbon ratio of the deposited products.

Because the reactor is cylindrical and symmetrical, its CFD model can be simplified to a two-dimensional axisymmetric model. The mass and heat transfer values were accounted via conservation of mass and conservation of momentum:

$$
\begin{gathered}
\nabla \cdot(\rho \mathbf{u})=0 \\
\rho(\mathbf{u} \cdot \nabla) \mathbf{u}=\nabla \cdot\left[-p \mathbf{I}+\mu\left(\nabla \mathbf{u}+(\nabla \mathbf{u})^{\mathrm{T}}-\frac{2}{3} \mu(\nabla \cdot \mathbf{u}) \mathbf{I}\right] .\right.
\end{gathered}
$$

Here $p$ is the fluid pressure; $\mu$ is the hydrodynamic viscosity; $\rho$ is the fluid density; $\mathbf{u}$ is the fluid velocity field; $\mathrm{T}$ is the temperature of the fluid; and $\mathbf{I}$ is unit tensor.

The chamber was heated through the induction of the graphite layer by the RF coil to generate eddy currents. Heat transfer occurred mainly through surface radiation and convection conduction, and electromagnetic phenomenon was neglected. The main governing equations are as follows:

$$
\rho C_{p} \mathbf{u} \cdot \nabla T+\nabla \cdot q=Q
$$

Here, $C_{p}$ is the fluid heat capacity; $Q$ is the heat source; and $q$ is the Fourier heat conduction. The radiative transfer equation (RTE) is used to describe the transfer 
process of radiant heat:

A beam of incident light propagates in the medium along the $\Omega$ direction and interacts with the medium. Part of the light intensity $I(\Omega)$ is partially absorbed by $k I(\Omega)$, and $k\left(m^{-1}\right)$ is the absorption coefficient; the other part of the light is along $\sigma_{s} I(\Omega)$ direction scattering, $\left(\sigma_{s} m^{-1}\right)$ is the scattering coefficient. The intensity of directional light will be attenuated by scattering in different directions, and will be enhanced by radiation in different directions. Therefore, this radiation process is described by the following equation:

$$
\Omega \cdot \nabla I(\Omega)=k I_{b}(T)-\left(k+\sigma_{s}\right) I(\Omega)+\frac{\sigma_{s}}{4 \pi} \int_{4 \pi} I\left(\Omega^{\prime}\right) \phi\left(\Omega^{\prime}, \Omega\right) d \Omega^{\prime}
$$

Here the probability of ray scattering from the direction of $\Omega^{\prime}$ to the direction of $\Omega$ is described by the scattering phase function $\phi\left(\Omega^{\prime}, \Omega\right) . k I_{b}$ represents the radiation of the medium in all directions, where $I_{b}$ is the intensity of the black body.

The most commonly used method for calculating the radiation transfer equation is the discrete coordinate method. The principle of this method is to calculate the ordinate component in the discrete direction. Therefore, it is still necessary to solve the intensity I by calculating the partial differential equation on each discrete ordinate:

$$
S_{i} \cdot \nabla I_{i}=k I_{b}(T)-\left(k+\sigma_{s}\right) I_{i}+\frac{\sigma_{s}}{4 \pi} \sum_{j=1}^{n} \omega_{j} I_{j} \phi\left(S_{j}, S_{i}\right)
$$

where $S_{i}$ is the discrete ordinate in the ith direction, and $\omega_{j}$ is the orthogonal weight.

For multi-component diffusion, the balance of the $i$ th chemical species includes the contribution of diffusion, convection and loss/production of species in $K$ gas phase reactions.

$$
\frac{\partial\left(\rho w_{i}\right)}{\partial t}=-\nabla \cdot\left(\rho \omega_{i} \vec{v}\right)-\nabla \cdot \vec{J}_{i}+M_{i} \sum_{k=1}^{K} v_{i k}\left(\mathfrak{R}_{k}^{g}-\mathfrak{R}_{-k}^{g}\right), i=1 . . N
$$

Among them, $\omega_{i}$ and $M_{i}$ represent the mass fraction and molecular weight of species $i$. The total mass and mole fraction are:

$$
\sum_{i=1}^{N} \omega_{i}=1
$$




$$
\sum_{i=1}^{N} x_{i}=1
$$

Diffusion flux $\left(\vec{J}_{i}\right)$ is the sum of concentration $\left(\vec{J}_{i}^{c}\right)$ and temperature gradient $\left(\vec{J}_{i}^{T}\right)$

$$
\begin{gathered}
\vec{J}_{i}=\vec{J}_{i}^{c}+\vec{J}_{i}^{T} \\
\vec{J}_{i}^{T}=-D_{i}^{T} \frac{\nabla T}{T} \quad i=1, N \\
\vec{J}_{i}^{c}=-\sum_{j=1}^{N}\left(\rho D_{i j}\right) \nabla \omega_{j} \quad i=1, N
\end{gathered}
$$

Here $D_{i j}$ and $D_{i}^{T}$ are the matrix of multi-component diffusion coefficient and multicomponent thermal diffusion coefficient, respectively. $D_{i}^{T}$ are calculated by gas kinetic theory, and specific information can be found in the literature [22]. The following formula was used to calculate the binary diffusion rate $\left(\mathrm{m}^{2} / \mathrm{s}\right)[23]$ :

$$
D_{i}=1.8829 \times 10^{-32} \frac{\sqrt{T^{3}\left(M_{A}+M_{B}\right) / M_{A} M_{B}}}{p \sigma_{A B} \Omega_{D}},
$$

where $M$ is molar mass; $\sigma$ is the minimum energy values of the characteristic length; $p$ is pressure; subscripts $\mathrm{A}$ and $\mathrm{B}$ indicate binary diffusion gas species; and $\Omega_{D}$ is the collision integral:

$$
\Omega_{D}=f\left(T, \sigma, \frac{\varepsilon}{k_{b}}, \mu_{D}\right)
$$

To calculate the collision integral $\Omega_{D}$, we need to define the minimum energy values of the characteristic length and Lennard-Jones interaction potential, which are $\sigma\left(10^{-10} \mathrm{~m}\right)$ and $\varepsilon / k_{b}(K)$, respectively. It is also necessary to provide a material dipole moment $\mu_{D}$ (Debye). The values were obtained from previous works [24], databases, or experiments (Table 2). $\sigma$ and $\varepsilon / k_{b}$ of $\mathrm{BCl}_{3}$ were approximated for the unknown coefficients of other boron-containing intermediates.

Table 2. Characteristic lengths of major substances $\left(\varepsilon / k_{b}\right)$ and Lennard-Jones interaction potential $(\sigma)$
Gas species
$\left(\varepsilon / k_{b}\right)(\mathrm{K})$
$\sigma(\AA)$ 


\begin{tabular}{ccc}
\hline $\mathrm{CH}_{4}$ & 154 & 3.78 \\
$\mathrm{C}_{2} \mathrm{H}_{2}$ & 209 & 4.1 \\
$\mathrm{C}_{2} \mathrm{H}_{4}$ & 280 & 3.97 \\
$\mathrm{C}_{2} \mathrm{H}_{6}$ & 252.3 & 4.302 \\
$\mathrm{HCl}$ & 344.7 & 3.339 \\
$\mathrm{H}_{2}$ & 38 & 2.92 \\
$\mathrm{BCl}_{3}$ & 337.7 & 5.127 \\
\hline
\end{tabular}

Here, the material dipole moment $\mu_{D}$ is uniformly zero.

The density of the mixed gas is expressed by the ideal gas equation:

$$
\begin{gathered}
\rho=\frac{P M}{R T} \\
M=\sum_{i=1}^{N} x_{i} M_{i}
\end{gathered}
$$

where $M$ is the molar mass of the mixed gas.

The detailed chemical kinetic model that describes gas-phase reactions in CVD has been presented in several studies. Table 3 lists 62 reversible reactions adopted for the gas model in the present case. Ge et al. [25-27] focused precisely on the thermodynamics of $\mathrm{Si}-\mathrm{C}-\mathrm{H}-\mathrm{Cl}$ systems. Moreover, the temperature conditions they studied are within the range of our research temperature. Therefore, for $\mathrm{C}-\mathrm{H}-\mathrm{Cl}$ systems (G1-G44 in Table 3), we preferentially adopted Ge's calculated data. Based on the most favorable reaction path previously proposed, $\mathrm{Su}$ et al. studied the reaction rate of the $\mathrm{BCl}_{3} / \mathrm{CH}_{4} / \mathrm{H}_{2}$ gas-phase system [28]. Their rate constants were calculated for temperatures within 200-2000 K and adopted here (G45-G58) [29]. Reinisch et al. reported a set of theoretical experiments of the gas-phase decomposition of boron trichloride in the presence of hydrogen radicals [30], and their reactions are also included (G59-G62 in Table 3).

Table 3. A list of gas phase reaction models 


\begin{tabular}{|c|c|c|c|c|}
\hline No & Reaction & $A\left(\mathrm{~s}^{-1}\right.$ or $\left.\mathrm{m}^{3} \mathrm{~mol}^{-1} \mathrm{~s}^{-1}\right)$ & $n$ & $E\left(\mathrm{kJmol}^{-1}\right)$ \\
\hline \multirow[t]{2}{*}{ G1 } & $\mathrm{CH}_{4} \rightarrow \mathrm{CH}_{3}+\mathrm{H}$ & $8.3 \times 10^{13}$ & 0 & 434.4 \\
\hline & reverse rate & $1.294 \times 10^{9}$ & -0.4 & 0 \\
\hline \multirow[t]{2}{*}{$\mathrm{G} 2$} & $\mathrm{C}_{2} \mathrm{H}_{4} \rightarrow \mathrm{C}_{2} \mathrm{H}_{2}+\mathrm{H}_{2}$ & $5.317 \times 10^{11}$ & 0.892 & 454.7 \\
\hline & reverse rate & 430.4 & 1.273 & 271.2 \\
\hline \multirow[t]{2}{*}{ G3 } & $\mathrm{C}_{2} \mathrm{H}_{5} \rightarrow \mathrm{C}_{2} \mathrm{H}_{4}+\mathrm{H}$ & $1.66 \times 10^{13}$ & 0.093 & 171.5 \\
\hline & reverse rate & $9.834 \times 10^{7}$ & 0.098 & 30.1 \\
\hline \multirow[t]{2}{*}{ G4 } & $\mathrm{C}_{2} \mathrm{H}_{6} \longrightarrow 2 \mathrm{CH}_{3}$ & $1.2 \times 10^{22}$ & -1.79 & 381 \\
\hline & reverse rate & $1.024 \times 10^{9}$ & -0.64 & 0 \\
\hline G5 & $\mathrm{C}_{2} \mathrm{H}_{6}+\mathrm{CH}_{2} \leftrightarrow \mathrm{C}_{2} \mathrm{H}_{5}+\mathrm{CH}_{3}$ & $1.2 \times 10^{8}$ & 0 & 0 \\
\hline G6 & $2 \mathrm{CH} \leftrightarrow \mathrm{C}_{2} \mathrm{H}_{2}$ & $1.204 \times 10^{8}$ & 0 & 0 \\
\hline G7 & $\mathrm{CH}_{2}+\mathrm{H} \leftrightarrow \mathrm{CH}+\mathrm{H}_{2}$ & $3.011 \times 10^{7}$ & 0 & 0 \\
\hline G8 & $\mathrm{CH}_{2}+\mathrm{CH} \leftrightarrow \mathrm{C}_{2} \mathrm{H}_{2}+\mathrm{H}$ & $3.975 \times 10^{7}$ & 0 & 0 \\
\hline G9 & $2 \mathrm{CH}_{2} \leftrightarrow \mathrm{C}_{2} \mathrm{H}_{4}$ & $1.024 \times 10^{6}$ & 0 & 0 \\
\hline G10 & $2 \mathrm{CH}_{2} \leftrightarrow \mathrm{C}_{2} \mathrm{H}_{2}+2 \mathrm{H}$ & $1.084 \times 10^{8}$ & 0 & 3.3 \\
\hline G11 & $2 \mathrm{CH}_{2} \leftrightarrow \mathrm{C}_{2} \mathrm{H}_{2}+\mathrm{H}_{2}$ & $1.204 \times 10^{7}$ & 0 & 3.3 \\
\hline G12 & $\mathrm{CH}_{3}+\mathrm{CH} \leftrightarrow \mathrm{C}_{2} \mathrm{H}_{3}+\mathrm{H}$ & $3.011 \times 10^{7}$ & 0 & 0 \\
\hline G13 & $\mathrm{CH}_{3}+\mathrm{CH}_{2} \leftrightarrow \mathrm{C}_{2} \mathrm{H}_{4}+\mathrm{H}$ & $1.807 \times 10^{7}$ & 0 & 0 \\
\hline \multirow[t]{2}{*}{ G14 } & $2 \mathrm{CH}_{3} \rightarrow \mathrm{C}_{2} \mathrm{H}_{5}+\mathrm{H}$ & $1.148 \times 10^{15}$ & 0 & 110 \\
\hline & reverse rate & $3.674 \times 10^{7}$ & 0 & 0 \\
\hline G15 & $\mathrm{CH}_{4}+\mathrm{CH} \leftrightarrow \mathrm{C}_{2} \mathrm{H}_{5}$ & $1.626 \times 10^{8}$ & 0 & 0 \\
\hline G16 & $\mathrm{CH}_{4}+\mathrm{CH} \leftrightarrow \mathrm{C}_{2} \mathrm{H}_{4}+\mathrm{H}$ & $3.011 \times 10^{7}$ & 0 & -1.6 \\
\hline G17 & $\mathrm{CH}_{4}+\mathrm{CH}_{2} \leftrightarrow \mathrm{C}_{2} \mathrm{H}_{6}$ & $1.024 \times 10^{7}$ & 0 & 0 \\
\hline G18 & $\mathrm{C}_{2} \mathrm{H}_{3}+\mathrm{M} \leftrightarrow \mathrm{C}_{2} \mathrm{H}_{2}+\mathrm{H}+\mathrm{M}$ & $3.011 \times 10^{9}$ & 0 & 133 \\
\hline \multirow[t]{2}{*}{ G19 } & $\mathrm{C}_{2} \mathrm{H}_{3}+\mathrm{H}_{2} \rightarrow \mathrm{C}_{2} \mathrm{H}_{4}+\mathrm{H}$ & $3.011 \times 10^{-2}$ & 2.63 & 36 \\
\hline & reverse rate & 1.325 & 2.53 & 51 \\
\hline G20 & $\mathrm{C}_{2} \mathrm{H}_{3}+\mathrm{CH}_{2} \leftrightarrow \mathrm{C}_{2} \mathrm{H}_{2}+\mathrm{CH}_{3}$ & $1.807 \times 10^{7}$ & 0 & 0 \\
\hline
\end{tabular}




\begin{tabular}{|c|c|c|c|c|}
\hline G21 & $\mathrm{C}_{2} \mathrm{H}_{3}+\mathrm{CH}_{3} \leftrightarrow \mathrm{C}_{2} \mathrm{H}_{2}+\mathrm{CH}_{4}$ & $3.914 \times 10^{5}$ & 0 & 0 \\
\hline G22 & $\mathrm{C}_{2} \mathrm{H}_{4}+\mathrm{M} \leftrightarrow \mathrm{C}_{2} \mathrm{H}_{2}+\mathrm{H}_{2}+\mathrm{M}$ & $1.5 \times 10^{9}$ & 0 & 233.6 \\
\hline G23 & $\mathrm{C}_{2} \mathrm{H}_{4}+\mathrm{M} \leftrightarrow \mathrm{C}_{2} \mathrm{H}_{3}+\mathrm{H}+\mathrm{M}$ & $1.4 \times 10^{10}$ & 0 & 344.8 \\
\hline \multirow[t]{2}{*}{ G24 } & $\mathrm{C}_{2} \mathrm{H}_{4}+\mathrm{H}_{2} \longrightarrow \mathrm{C}_{2} \mathrm{H}_{5}+\mathrm{H}$ & $1.024 \times 10^{7}$ & 0 & 285 \\
\hline & reverse rate & $1.807 \times 10^{6}$ & 0 & 0 \\
\hline G25 & $\mathrm{C}_{2} \mathrm{H}_{4}+\mathrm{C}_{2} \mathrm{H}_{2} \leftrightarrow 2 \mathrm{C}_{2} \mathrm{H}_{3}$ & $2.409 \times 10^{7}$ & 0 & 286 \\
\hline \multirow[t]{2}{*}{ G26 } & $2 \mathrm{C}_{2} \mathrm{H}_{4} \rightarrow \mathrm{C}_{2} \mathrm{H}_{3}+\mathrm{C}_{2} \mathrm{H}_{5}$ & $4.818 \times 10^{8}$ & 0 & 299 \\
\hline & reverse rate & $4.818 \times 10^{5}$ & 0 & 0 \\
\hline G27 & $\mathrm{CH}_{4}+\mathrm{CH}_{3} \leftrightarrow \mathrm{C}_{2} \mathrm{H}_{5}+\mathrm{H}_{2}$ & $1.024 \times 10^{7}$ & 0 & 95.6 \\
\hline \multirow[t]{2}{*}{ G28 } & $\mathrm{C}_{2} \mathrm{H}_{5}+\mathrm{H}_{2} \rightarrow \mathrm{C}_{2} \mathrm{H}_{6}+\mathrm{H}$ & $3.071 \times 10^{-6}$ & 3.6 & 35 \\
\hline & reverse rate & $1.445 \times 10^{3}$ & 1.5 & 31 \\
\hline G29 & $\mathrm{C}_{2} \mathrm{H}_{5}+\mathrm{CH}_{3} \leftrightarrow \mathrm{C}_{2} \mathrm{H}_{4}+\mathrm{CH}_{4}$ & $1.987 \times 10^{7}$ & 0.5 & 0 \\
\hline \multirow[t]{2}{*}{ G30 } & $\mathrm{C}_{2} \mathrm{H}_{6}+\mathrm{CH}_{3} \rightarrow \mathrm{C}_{2} \mathrm{H}_{5}+\mathrm{CH}_{4}$ & $0.549 \times 10^{-3}$ & 4 & 34.6 \\
\hline & reverse rate & $8.618 \times 10^{-8}$ & 4.14 & 52.6 \\
\hline G31 & $2 \mathrm{C}_{2} \mathrm{H}_{5} \leftrightarrow \mathrm{C}_{2} \mathrm{H}_{6}+\mathrm{C}_{2} \mathrm{H}_{4}$ & $7.227 \times 10^{6}$ & 0 & 4.5 \\
\hline \multirow[t]{2}{*}{ G32 } & $\mathrm{C}_{2} \mathrm{H}_{5}+\mathrm{C}_{2} \mathrm{H}_{4} \rightarrow \mathrm{C}_{2} \mathrm{H}_{6}+\mathrm{C}_{2} \mathrm{H}_{3}$ & $6.624 \times 10^{-4}$ & 3.13 & 75.4 \\
\hline & reverse rate & $6.022 \times 10^{-4}$ & 3.3 & 43.9 \\
\hline \multirow[t]{2}{*}{ G33 } & $\mathrm{C}_{2} \mathrm{H}_{2}+\mathrm{C}_{2} \mathrm{H}_{6} \rightarrow \mathrm{C}_{2} \mathrm{H}_{3}+\mathrm{C}_{2} \mathrm{H}_{5}$ & 104.4 & 2.05 & 292.8 \\
\hline & reverse rate & $5.553 \times 10^{7}$ & -0.346 & 46.4 \\
\hline \multirow[t]{2}{*}{ G34 } & $\mathrm{C}_{2} \mathrm{H}_{4} \rightarrow \mathrm{C}_{2} \mathrm{H}_{3}+\mathrm{H}$ & $4.365 \times 10^{12}$ & 0.945 & 451.6 \\
\hline & reverse rate & $8.428 \times 10^{7}$ & 0 & 0 \\
\hline \multirow[t]{2}{*}{ G35 } & $2 \mathrm{CH}_{3} \rightarrow \mathrm{CH}_{2}+\mathrm{CH}_{4}$ & 0.0152 & 3.153 & 64.6 \\
\hline & reverse rate & 62.25 & 2.451 & 54.8 \\
\hline \multirow[t]{2}{*}{ G36 } & $\mathrm{CH}_{2}+\mathrm{HCl} \rightarrow \mathrm{CH}_{3}+\mathrm{Cl}$ & 183.417 & 1.71 & 8.9 \\
\hline & reverse rate & 39.6 & 2.24 & 31.8 \\
\hline \multirow[t]{2}{*}{ G37 } & $\mathrm{CH}_{3}+\mathrm{Cl} \rightarrow \mathrm{CH}_{2}+\mathrm{HCl}$ & $2.2 \times 10^{7}$ & 0 & 34.5 \\
\hline & reverse rate & $1.698 \times 10^{6}$ & 0 & 3.63 \\
\hline G38 & $\mathrm{C}_{2} \mathrm{H}_{5}+\mathrm{HCl} \rightarrow \mathrm{C}_{2} \mathrm{H}_{6}+\mathrm{Cl}$ & 0.0123 & 2.29 & 0 \\
\hline
\end{tabular}




\begin{tabular}{|c|c|c|c|c|}
\hline & reverse rate & $1.4365 \times 10^{4}$ & 1.476 & 8.4 \\
\hline \multirow[t]{2}{*}{ G39 } & $\mathrm{CH}_{3}+\mathrm{HCl} \rightarrow \mathrm{CH}_{4}+\mathrm{Cl}$ & 70.106 & 1.412 & 15.7 \\
\hline & reverse rate & $1.642 \times 10^{-7}$ & 4.51 & 5.9 \\
\hline \multirow[t]{2}{*}{ G40 } & $\mathrm{H}_{2}+\mathrm{H} \rightarrow 3 \mathrm{H}$ & $2.228 \times 10^{8}$ & 0 & 402 \\
\hline & reverse rate & $9.792 \times 10^{5}$ & -1 & 0 \\
\hline \multirow[t]{2}{*}{ G41 } & $2 \mathrm{H}_{2} \rightarrow 2 \mathrm{H}+\mathrm{H}_{2}$ & $9.033 \times 10^{8}$ & 0 & 402 \\
\hline & reverse rate & $9.792 \times 10^{4}$ & -0.6 & 0 \\
\hline G42 & $2 \mathrm{H}+\mathrm{M} \leftrightarrow \mathrm{H}_{2}+\mathrm{M}$ & $5.44 \times 10^{12}$ & -1.3 & 0 \\
\hline \multirow[t]{2}{*}{ G43 } & $\mathrm{HCl} \rightarrow \mathrm{H}+\mathrm{Cl}$ & $1.109 \times 10^{17}$ & -0.681 & 417.6 \\
\hline & reverse rate & 96.39 & 1.87 & -35.2 \\
\hline \multirow[t]{2}{*}{ G44 } & $\mathrm{Cl}+\mathrm{H}_{2} \rightarrow \mathrm{HCl}+\mathrm{H}$ & $7.52 \times 10^{-4}$ & 3.39 & -4.9 \\
\hline & reverse rate & $4.379 \times 10^{8}$ & -0.091 & 35.4 \\
\hline \multirow[t]{2}{*}{ G45 } & $\mathrm{BCl}_{3} \rightarrow \mathrm{BCl}_{2}+\mathrm{Cl}$ & $5.85 \times 10^{13}$ & 0.31 & 464.1 \\
\hline & reverse rate & $2.74 \times 10^{8}$ & 1.44 & 17.88 \\
\hline \multirow[t]{2}{*}{ G46 } & $\mathrm{CH}_{4}+\mathrm{BCl}_{3} \rightarrow \mathrm{CH}_{3} \mathrm{BCl}_{2}+\mathrm{HCl}$ & $2.08 \times 10^{7}$ & 1.43 & 194.8 \\
\hline & reverse rate & $2.4 \times 10^{8}$ & 0.5 & 148.4 \\
\hline \multirow[t]{2}{*}{ G47 } & $\mathrm{CH}_{3} \mathrm{BCl}_{2} \rightarrow \mathrm{CH}_{2} \mathrm{BCl}_{2}+\mathrm{H}$ & $1.98 \times 10^{8}$ & 1.6 & 348.2 \\
\hline & reverse rate & $4.29 \times 10^{8}$ & 1.23 & 12.7 \\
\hline \multirow[t]{2}{*}{ G48 } & $\mathrm{CH}_{3} \mathrm{BCl}_{2}+\mathrm{Cl} \rightarrow \mathrm{CH}_{2} \mathrm{BCl}_{2}+\mathrm{HCl}$ & $8.67 \times 10^{6}$ & 1.79 & 5.43 \\
\hline & reverse rate & $1.76 \times 10^{6}$ & 1.78 & 53.0 \\
\hline \multirow[t]{2}{*}{ G49 } & $\mathrm{CH}_{2} \mathrm{BCl}_{2} \rightarrow \mathrm{CHBCl}_{2}+\mathrm{H}$ & $1.5 \times 10^{16}$ & -0.79 & 218.75 \\
\hline & reverse rate & $6.2 \times 10^{15}$ & -0.87 & 55.4 \\
\hline \multirow[t]{2}{*}{ G50 } & $\mathrm{CHBCl}_{2}+\mathrm{H} \rightarrow \mathrm{CHBCl}+\mathrm{HCl}$ & $1.05 \times 10^{9}$ & 1.36 & 38.58 \\
\hline & reverse rate & $4.6 \times 10^{5}$ & 2.16 & 127.6 \\
\hline \multirow[t]{2}{*}{ G51 } & $\mathrm{CHBCl}+\mathrm{Cl} \rightarrow \mathrm{CBCl}+\mathrm{HCl}$ & $2.67 \times 10^{14}$ & -0.48 & 247.49 \\
\hline & reverse rate & $6.4 \times 10^{11}$ & 0.048 & 159.2 \\
\hline \multirow[t]{2}{*}{ G52 } & $\mathrm{CBCl}+\mathrm{H} \rightarrow \mathrm{CHBCl}$ & $4.58 \times 10^{11}$ & 0.89 & 2.69 \\
\hline & reverse rate & $1.05 \times 10^{25}$ & 0.77 & 18.61 \\
\hline
\end{tabular}




\begin{tabular}{|c|c|c|c|c|}
\hline \multirow[t]{2}{*}{ G53 } & $\mathrm{CHBCl} \rightarrow \mathrm{BC}+\mathrm{HCl}$ & $7.0 \times 10^{13}$ & -0.024 & 30.12 \\
\hline & reverse rate & $1.17 \times 10^{8}$ & 1.64 & 39.2 \\
\hline \multirow{2}{*}{ G54 } & $\mathrm{BCl}_{3}+\mathrm{H}_{2} \rightarrow \mathrm{BHCl}_{2}+\mathrm{HCl}$ & $1.26 \times 10^{9}$ & 1.11 & 191.3 \\
\hline & reverse rate & $2.24 \times 10^{4}$ & 2.13 & 99.65 \\
\hline \multirow[t]{2}{*}{ G55 } & $\mathrm{BHCl}_{2}+\mathrm{H} \rightarrow \mathrm{BH}_{2} \mathrm{Cl}_{2}$ & $3.29 \times 10^{9}$ & 1.28 & 7.15 \\
\hline & reverse rate & $3.52 \times 10^{25}$ & 0.58 & 0.98 \\
\hline \multirow[t]{2}{*}{ G56 } & $\mathrm{BH}_{2} \mathrm{Cl}_{2} \rightarrow \mathrm{BCl}_{2}+\mathrm{H}_{2}$ & $2.25 \times 10^{15}$ & -0.69 & 54.83 \\
\hline & reverse rate & $6.68 \times 10^{9}$ & 0.47 & 64.8 \\
\hline \multirow[t]{2}{*}{ G57 } & $\mathrm{BCl}_{2} \rightarrow \mathrm{BCl}+\mathrm{Cl}$ & $1.90 \times 10^{12}$ & 0.47 & 305.5 \\
\hline & reverse rate & $1.4 \times 10^{10}$ & 1.13 & 4.14 \\
\hline \multirow[t]{2}{*}{ G58 } & $\mathrm{BCl}+\mathrm{H} \rightarrow \mathrm{B}+\mathrm{HCl}$ & $2.37 \times 10^{12}$ & 0.47 & 112.7 \\
\hline & reverse rate & $3.27 \times 10^{10}$ & 1.05 & 4.76 \\
\hline G59 & $\mathrm{BCl}_{3}+\mathrm{H} \rightarrow \mathrm{BHCl}_{3}$ & $2.33 \times 10^{7}$ & -0.54 & 13.23 \\
\hline G60 & $\mathrm{BCl}_{3}+\mathrm{H} \rightarrow \mathrm{BHCl}_{2}+\mathrm{Cl}$ & $2.31 \times 10^{3}$ & 1.36 & 44.8 \\
\hline G61 & $\mathrm{BCl}_{3}+\mathrm{H} \rightarrow \mathrm{BCl}_{2}+\mathrm{HCl}$ & $4.09 \times 10^{3}$ & 0.97 & 49.8 \\
\hline G62 & $\mathrm{BCl}_{3}+\mathrm{H} \rightarrow \mathrm{BCl}_{2}+\mathrm{HCl}$ & $2.6 \times 10^{4}$ & 1.23 & 108.4 \\
\hline
\end{tabular}

a The rate constants are written according to Arrhenius equation: K=ATne-E/RT. “ $\leftrightarrow$ ” denotes the reverse rates are calculated from equilibrium thermochemistry.

\subsection{Machine learning (ML)}

With the great success of data-driven modeling, machine learning (ML) has received increasing attention [31-34]. Considering the production of the variety of intermediate species and the complexity of the deposition process of the CVD- $\mathrm{B}_{\mathrm{x}} \mathrm{C}$, we combined a reactor model (RM) with $\mathrm{ML}$, as shown in Figure 2. Considering $N$ arbitrary samples $\left(X_{i}, t_{i}\right) \quad, \quad$ where $\quad X_{i}=\left[x_{i 1}, x_{i 2}, \cdots, x_{i n}\right]^{T} \in R^{n}, t_{i}=$ $\left[t_{i 1}, t_{i 2}, \cdots, t_{i m}\right]^{T} \in R^{m} . X_{i}$ represent the input data set, and $t_{i}$ is the output data set. 


$$
X_{i}=\left\{\begin{array}{ccccc}
x_{1}(T), & x_{1}\left(B C l_{3}\right), & x_{1}\left(C H_{4}\right), & \cdots, & x_{1}\left(B H C l_{2}\right), \\
x_{2}(T), & x_{2}\left(B C l_{3}\right), & x_{2}\left(C H_{4}\right), & \cdots, & x_{2}\left(B H C l_{2}\right), \\
\cdots, & \cdots, & \cdots, & \cdots, & \cdots, \\
x_{N}(T), & x_{N}\left(B C l_{3}\right), & x_{N}\left(C H_{4}\right), & \cdots, & x_{N}\left(B H C l_{2}\right),
\end{array}\right\}
$$

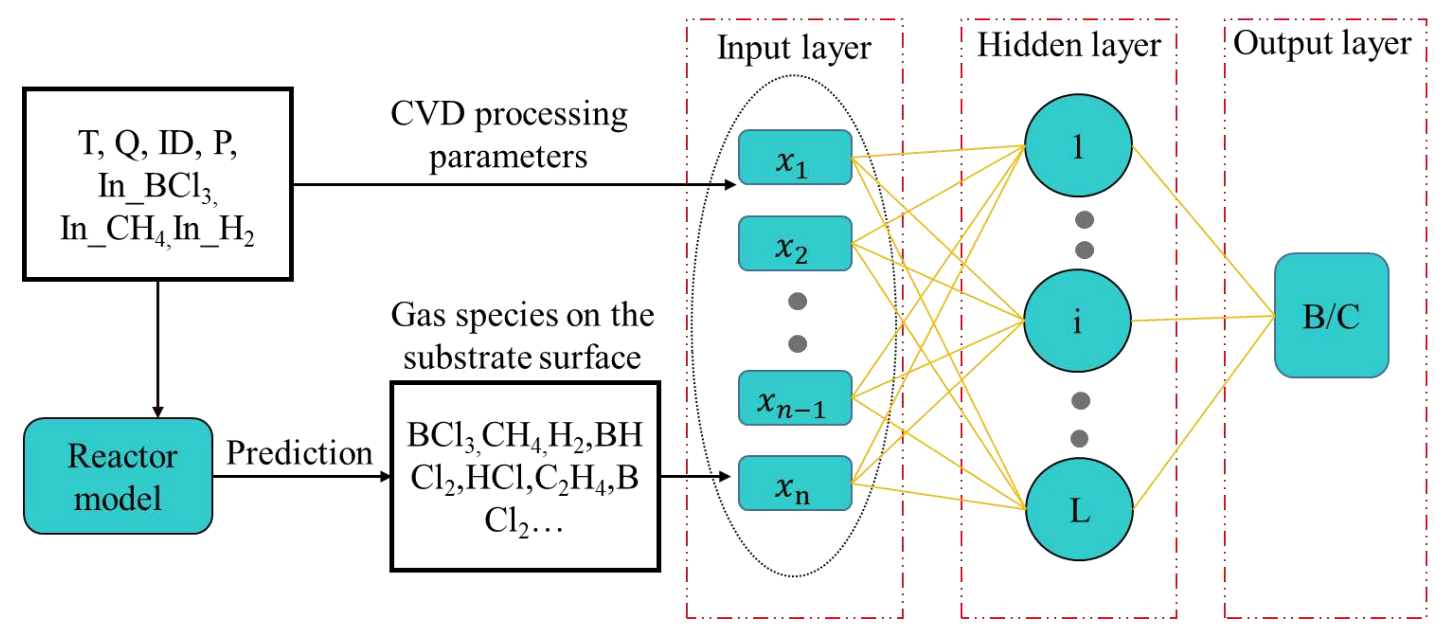

Fig 2. ML model design for $\mathrm{B} / \mathrm{C}$ prediction.

Error back propagation algorithm (BP) and support vector machine (SVM) are two commonly used machine learning algorithms. They have many applications in materials research $[35,36]$; thus, they are applied in ML. The BP algorithm is composed of two processes: forward calculation of data stream (forward propagation) and backward propagation of error signal. In forward propagation, the propagation direction is from the input layer to the hidden layer and then to the output layer. The state of each layer of neurons only affects the next layer of neurons. However, if the actual output does not match the expected output, the process of back propagation of errors is then entered. Error backpropagation involves passing the output error back to the input layer through the hidden layer, layer by layer, apportioning the error to all units of each layer, and using the error signal obtained from each layer as the basis for adjusting the weight of each unit. Through these two processes alternately, the error function gradient descent strategy is performed in the weight vector space, and a set of weight vectors is dynamically searched to achieve the minimum network error function value. Learning rate and learning error of $\mathrm{BP}$ neural network structure are set as 0.01 and 0.001 , respectively. Considering the network accuracy and calculation time, three layers of BP neural network structure are selected, and the number of the hidden layer nodes is 
chosen as 10 by trial-and-error techniques. The $\mathrm{N}$ arbitrary samples $\left(X_{i}, t_{i}\right)$ were entered into the BP neural algorithm program, and the specific steps are as follows:

(1) Initialize the network, and randomly assign each connection weight [w],[v] and threshold values $\theta_{i}, r_{t}$;

(2) Compute hidden layers from a given input-output mode pair;

(3) Calculate new connection weights and thresholds;

(4) Select the next input mode pair to return to the second step, and repeat the training until the network output error reaches the required training.

The SVM algorithm is very powerful; it not only supports linear and nonlinear classification but also linear and nonlinear regression [37]. In the process of determining the hyperplane with the largest geometric interval, only the sample points closest to the hyperplane play a role. Such sample points are called support vectors. This classification model is also called support vector machine. In practical problems, data is usually not linearly separable in a multidimensional space; that is, in the input space where the data is located, there is no hyperplane that can complete the required classification. A feasible solution is to apply kernel techniques to map data from the input space to a higher dimensional space through a specific function and look for hyperplanes in the higher dimensional space. We call this space a feature space. Because the input space is mapped to a higher dimensional feature space through specific mapping, the amount of calculation in the higher dimensional space will increase significantly, and the computational complexity will also increase significantly.

In the SVM regression, the system attempts to fit as many data as possible into the interval while limiting the margin violation. To reduce the amount of calculation, on the premise that the calculation of the support vector machine involves only the inner product calculation, a kernel function is introduced to convert the inner product calculation in the feature space into a non-linear transformation of the inner product operation of the data in the input space. SVM needs to adjust the relevant parameters, 
mainly penalty parameter (denoted as C) and nuclear function parameter (denoted as $\mathrm{G})$, to get a better predictive accuracy. C demonstrate how much you value outliers, the greater the C, the less you want to lose them, thus lead to overfitting more likely. G implicitly determines the distribution of the data after mapping to the new feature space. the larger the G, the less the support vector. The number of support vectors affects the speed of training and prediction. With regard to the optimization of $\mathrm{C}$ and $\mathrm{G}$, the generally accepted method is to search the optimum values in a certain range. Here $\mathrm{C}$ and $\mathrm{G}$ are considered as 2.3 and 4 by grid-search techniques.

It is essential to assess the error during prediction in order to evaluate the performance of BP and SVM models. This could be carried out by comparing the model predicted value and the experimentally measured values. In this regard, mean absolute percentage error (MAPE) and mean square error (MSE) were employed to assess the closeness of prediction values and measured values.

$$
\begin{gathered}
M A P E=\frac{100}{n} \sum_{i=1}^{n} \frac{\left|E_{i}-P_{i}\right|}{E_{i}}, \\
M S E=\frac{100}{n} \sum_{i=1}^{n}\left(E_{i}-P_{i}\right)^{2} .
\end{gathered}
$$

where $E_{i}$ is the measured experimental value; $P_{i}$ indicates the ML model predicted result; and $\mathrm{n}$ refers to the total number of sample points.

\section{Results and discussion}

\subsection{Temperature field distribution}

The temperature distribution of the reactor is shown in Figure 3. The results show that the temperature distribution in the reactor shows a gradient distribution, and the temperature around the deposition substrate was highest, which is consistent with the actual processing temperature. The temperature distribution in the middle deposition area is relatively uniform (isothermal zone). Due to the size effect of the reactor and the 
cooling effect of the gas, the temperature gradient near the inlet and outlet of the isothermal zone was relatively large. The precursor was gradually heated and decomposed into a large amount of intermediate species when entering the isothermal zone, and then these intermediate species reacted on the substrate surface.

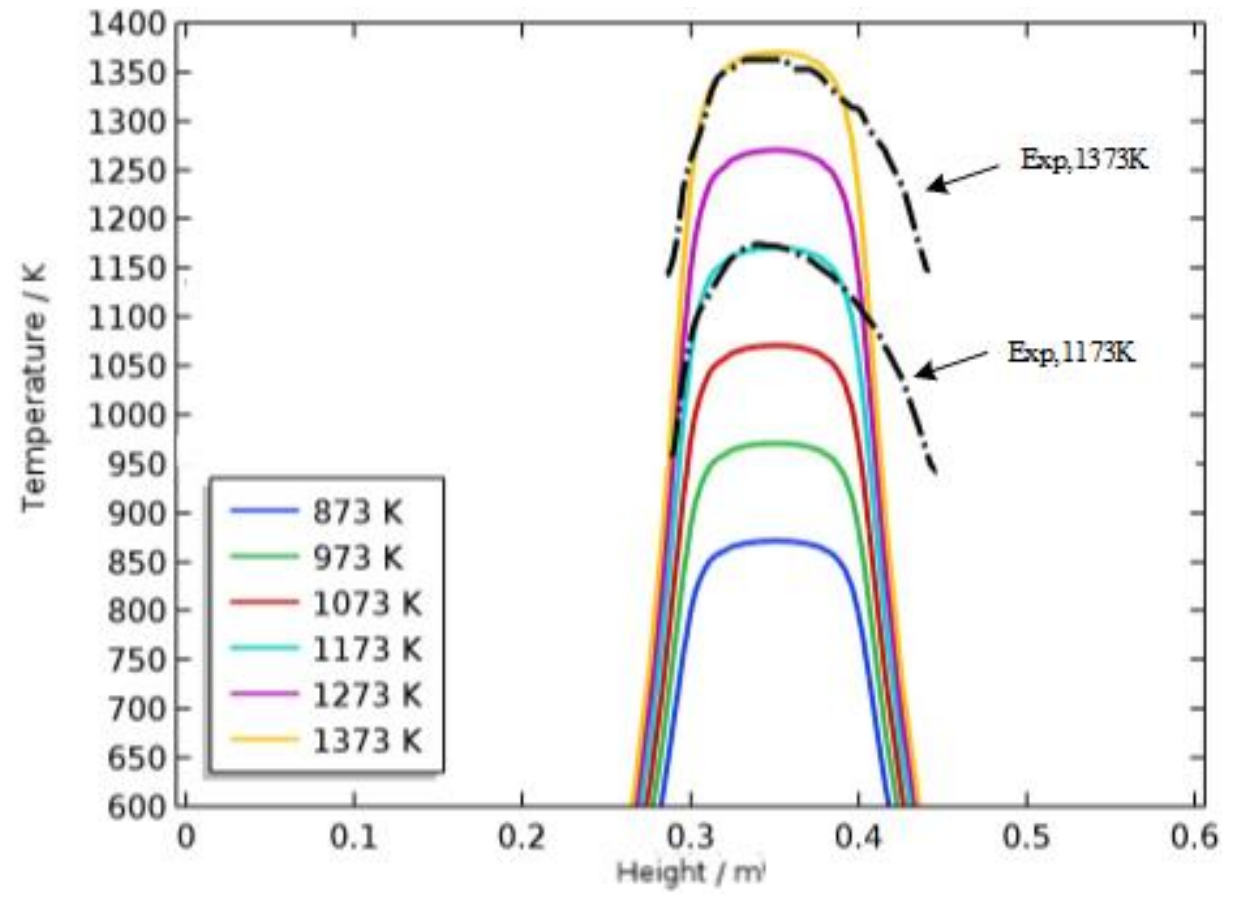

Fig 3. Axial temperature distribution curve in the reactor at different deposition temperatures.

\subsection{Distribution of intermediate species}

The distribution of the molar fraction of the intermediate species in the reactor is shown in Figure 4. The concentration of $\mathrm{BCl}_{3}$ dropped sharply as it approached the substrate, which was consistent with the temperature distribution trend inside the reaction chamber. The main decomposed gas species of $\mathrm{BCl}_{3}$ in the reaction chamber were $\mathrm{BHCl}_{2}$ and $\mathrm{HCl}$, and the trends of $\mathrm{BHCl}_{2}$ and $\mathrm{HCl}$ were the same, which was consistent with the main reaction $\mathrm{BCl}_{3}+\mathrm{H}_{2} \rightarrow \mathrm{BHCl}_{2}+\mathrm{HCl}$ [13]. $\mathrm{BHCl}_{2}$ was considered an intermediate and/or by-product, which were formed by hydrogen reduction of $\mathrm{BCl}_{3}$, according to thermodynamic analysis and experimental work [13, 38]. Berjonneau et al. showed that in the case of a homogeneous reaction, $\mathrm{CH}_{4}$ still exists in a large amount at high temperature, and in the case of a heterogeneous reaction, 
$\mathrm{CH}_{4}$ will decompose to form boron carbide and graphite as a carbon source [13]. The above situation agrees with our prediction. In addition, we found that some intermediate gas phase components, such as $\mathrm{BCl}_{2}, \mathrm{BCl}, \mathrm{BH}_{2} \mathrm{Cl}_{2}, \mathrm{CHBCl}_{2}, \mathrm{CHBCl}, \mathrm{CH}_{3}, \mathrm{C}_{2} \mathrm{H}_{3}, \mathrm{C}_{2} \mathrm{H}_{5}$, and $\mathrm{C}_{2} \mathrm{H}_{6}$, have lower molar fractions, indicating that they do not play a dominant role in the $\mathrm{B} / \mathrm{C}$ ratio of the deposited product during the homogeneous reaction. In addition, Reinisch et al. proved that $\mathrm{MDB}\left(\mathrm{CH}_{3} \mathrm{BCl}_{2}\right)$ was a major intermediate component by FTIR apparatus [20]. Correspondingly, Figure 4 show MDB is the third important boron intermediate whose concentration is only lower than $\mathrm{BHCl}_{3}$ and $\mathrm{BHCl}_{2}$. The results obtained from Reinisch et al. and our model agree well with each other. 

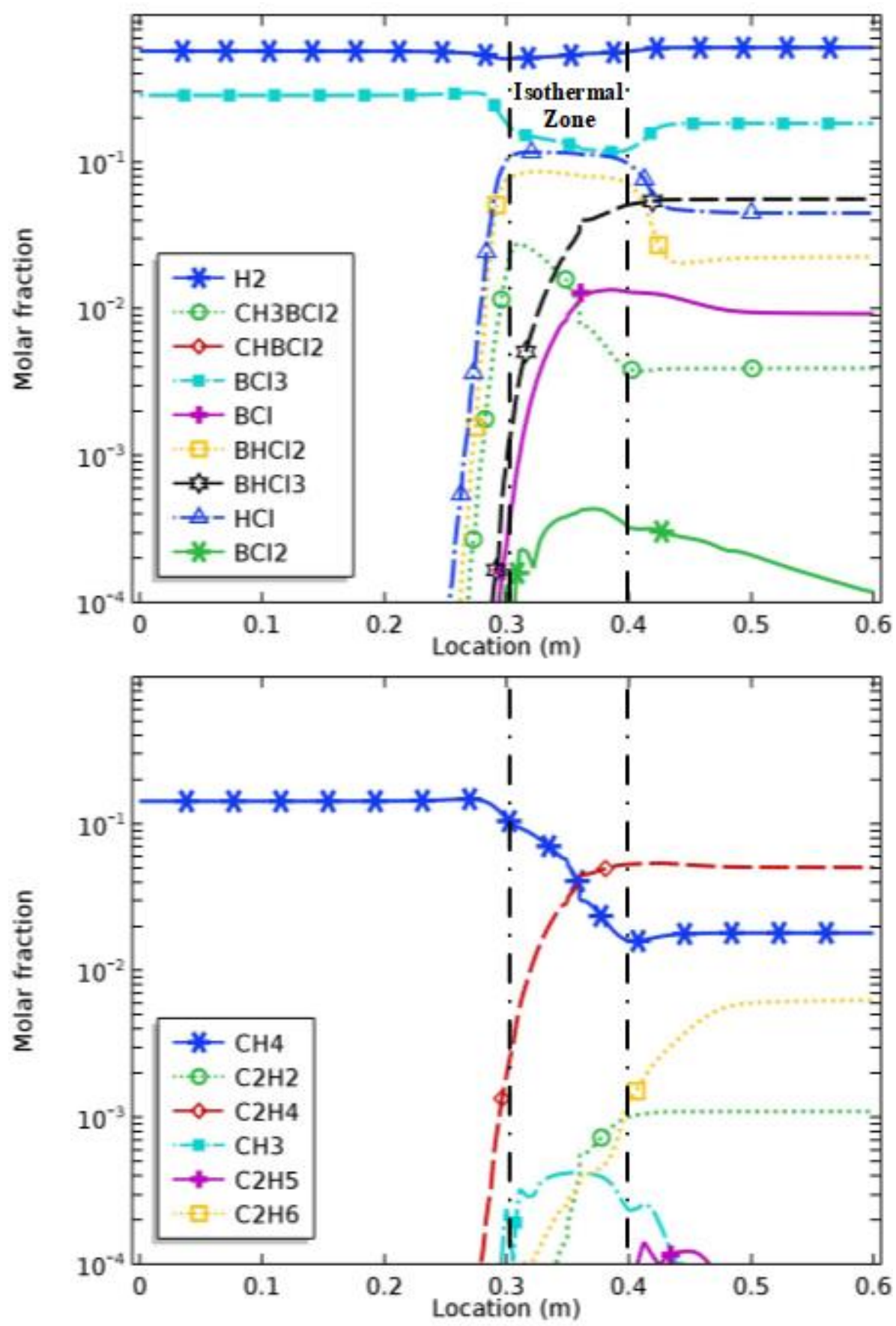

Fig 4. Plot of the gas-phase compositions along the reactor height: for deposition temperature of $1000^{\circ} \mathrm{C}$, total pressure of $12 \mathrm{kPa}$, total gas flow rate of $210 \mathrm{sccm}, \mathrm{In}_{-} \mathrm{BCl}_{3}$ is $2 / 7$ and $\mathrm{In}_{-} \mathrm{CH}_{4}$ is $1 / 7$.

Figure 5 shows the predicted mole fractions of important species at different temperatures, with a constant feed gas composition and inlet flow rate. The concentrations are the mean values at the substrate surface. Only the major chemical species having a molar fraction larger than $10^{-4}$ are shown. Low temperature $\left(900^{\circ} \mathrm{C}\right)$ 
leads to less decomposition of $\mathrm{BCl}_{3}$ and $\mathrm{CH}_{4} . \mathrm{BHCl}_{2}$ has the highest concentration, compared to other boron-containing intermediate species. The decomposition of $\mathrm{CH}_{4}$ is very sensitive to temperature. Remarkably, at $950{ }^{\circ} \mathrm{C}$, the concentration of hydrocarbon increased with temperature, for example, $\mathrm{C}_{2} \mathrm{H}_{2}$ and $\mathrm{C}_{2} \mathrm{H}_{4}$. The concentration of $\mathrm{CH}_{4}$ slightly decreased with increasing temperature, and $\mathrm{C}_{2} \mathrm{H}_{4}$ became the most abundant carbon intermediate. Further, $\mathrm{C}_{2} \mathrm{H}_{2}$ became the second largest hydrocarbon species at higher temperature. The shift from $\mathrm{CH}_{4}$ to $\mathrm{C}_{2} \mathrm{H}_{2}$ at high temperatures has also been found in hydrocarbon cracking chemistry $(\mathrm{C}-\mathrm{H}$ system, without $\mathrm{B}$ nor $\mathrm{Cl}$ ). These results demonstrate that the major hydrocarbon species are $\mathrm{CH}_{4}$ and $\mathrm{C}_{2} \mathrm{H}_{4}$, and the major silicon-containing species containing boron are $\mathrm{BCl}_{3}$, $\mathrm{BHCl}_{2}, \mathrm{BHCl}_{3}$, and $\mathrm{CH}_{3} \mathrm{BCl}_{2}$ for a typical $\mathrm{CMC}$ processing temperature. Our predictions are consistent with Berjonneau's experimental results and thermodynamic calculation [37].

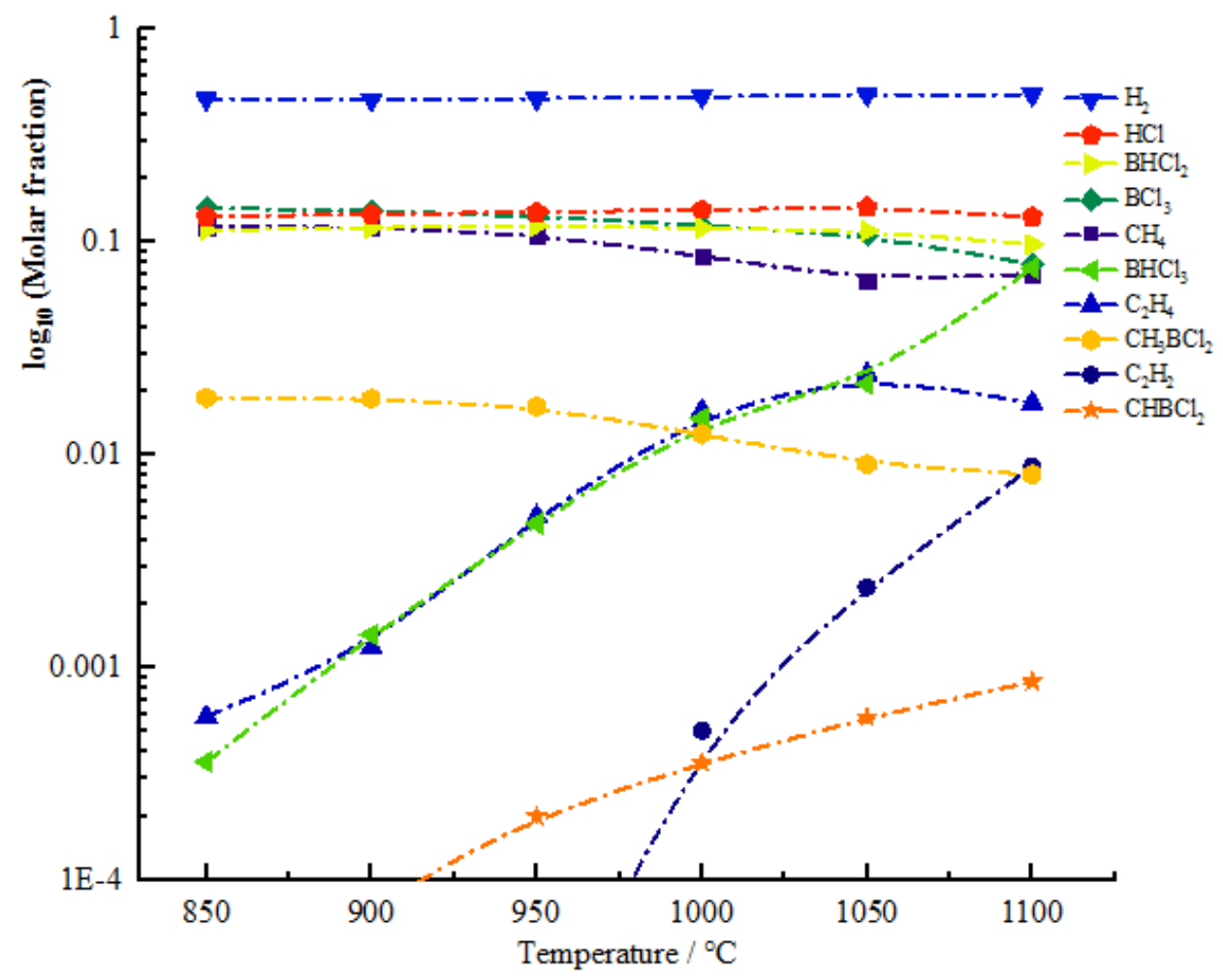

Fig 5. Influence of temperature on the mole fraction of intermediate components. total pressure of $12 \mathrm{kPa}$, total gas flow rate of $210 \mathrm{sccm}, \mathrm{In}_{-} \mathrm{BCl}_{3}$ is $2 / 7$ and $\mathrm{In}_{-} \mathrm{CH}_{4}$ is $1 / 7$. 


\subsection{Predicted boron to carbon ratio}

Firstly, BP and SVM were used to directly correlate the deposition atomic ratio with deposition conditions (temperature, input gas ratio, total pressure, reactor inner diameter and flow rate), without the reactor-scale model. Figures 6 and 8 show that the functional relationship between them is not very good $\left(\mathrm{R}^{2}=0.9388\right)$. The average values of MSE and MAPE are approximately $25 \%$ and $30 \%$, respectively.

Next, a reactor-scale model was established to predict the molar fraction of the intermediate gas species generated in various deposition processes. Then, we used BP and SVM to relate the boron-carbon ratio values of MSE and MAPE were around $6.8 \%$ and $8.2 \%$, respectively. Figures 7 and 9 show that the experimental measured results and predicted values are close to overlapping $\left(\mathrm{R}^{2}=0.975\right)$. As shown in Table 5, after inputting the intermediate gas species predicted by reactor-scale model into the SVM algorithm, the prediction error was reduced from $25 \%$ to $7 \%$. Compared with the BP algorithm, the prediction of SVM was better. The prediction of SVM was determined by the algorithm itself and affected by the sample size. In the case of small sample data, SVM is recommended.

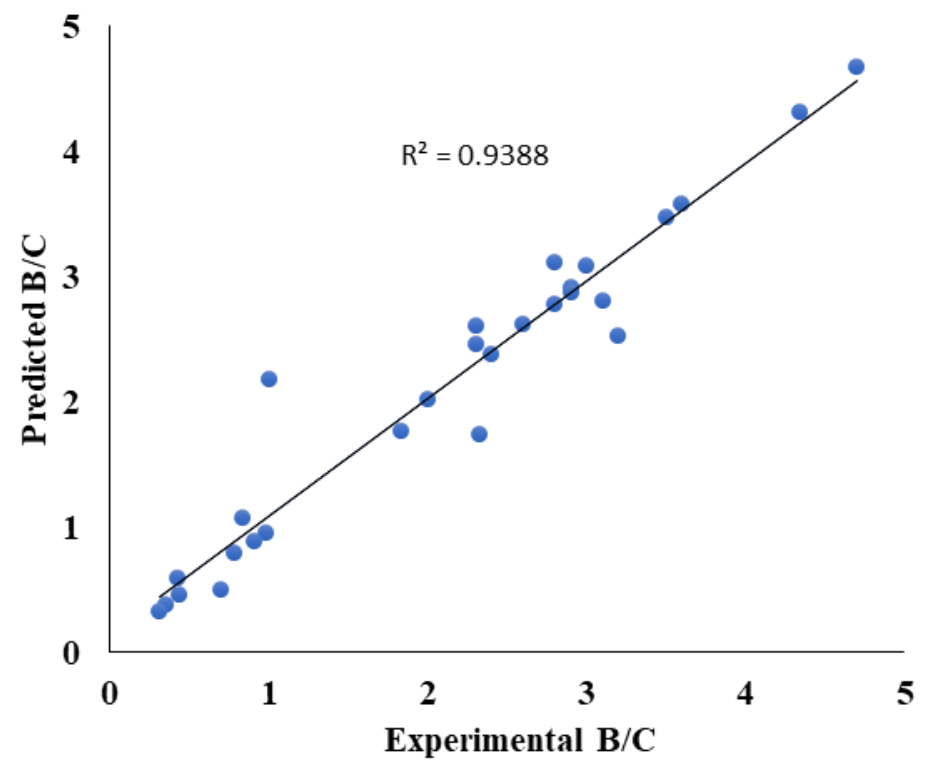

Fig 6. Goodness of fit (input variables are T, Q, $\mathrm{P}, \mathrm{In}_{-} \mathrm{BCl}_{3}$, In_C $\mathrm{CH}_{4}$, and $\mathrm{In}_{-} \mathrm{H}_{2}$ ). 


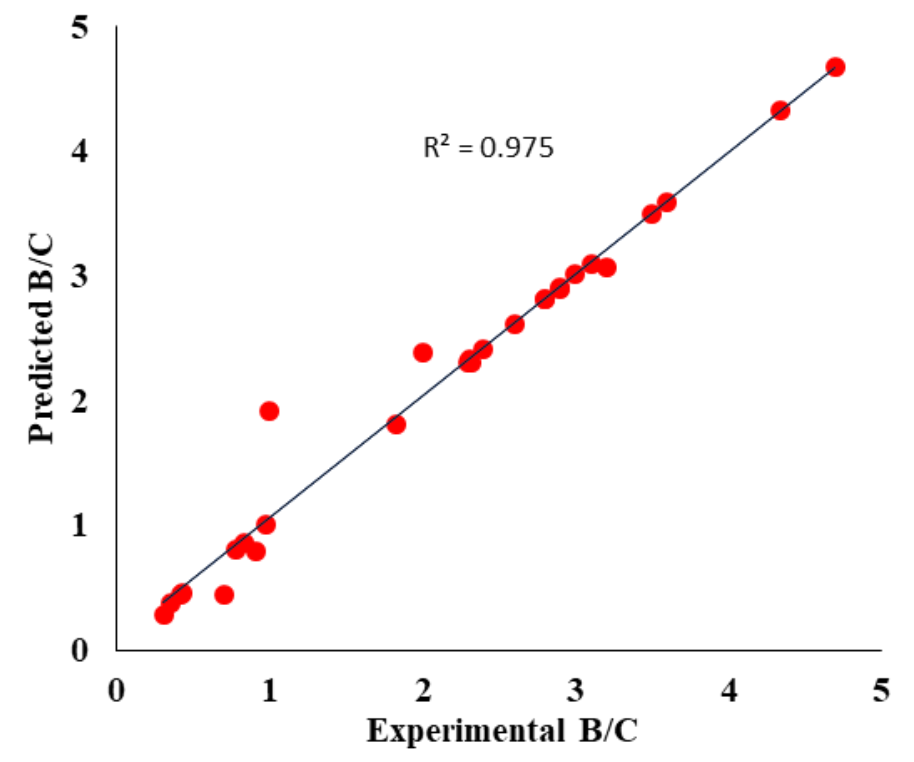

Fig 7. Goodness of fit (input variables are T, $\mathrm{P}, \mathrm{BCl}_{3}, \mathrm{CH}_{4}, \mathrm{BHCl}_{2}, \mathrm{BHCl}_{3}, \mathrm{BCl}_{2}, \mathrm{HCl}$, and $\left.\mathrm{H}_{2}\right)$.

Table 5. Mean absolute percentage error and mean square error of predicted results

\begin{tabular}{|c|c|c|c|c|}
\hline & & SVM & $\mathrm{BP}$ & Average value \\
\hline \multirow{2}{*}{$\begin{array}{l}\text { Without } \\
\text { reactor-scale }\end{array}$} & MSE & $16.5 \%$ & $34.2 \%$ & $25.35 \%$ \\
\hline & MAPE & $15.8 \%$ & $45.6 \%$ & $30.7 \%$ \\
\hline \multirow{2}{*}{$\begin{array}{l}\text { With reactor- } \\
\text { scale }\end{array}$} & MSE & $1.7 \%$ & $11.9 \%$ & $6.8 \%$ \\
\hline & MAPE & $8.4 \%$ & $8.1 \%$ & $8.25 \%$ \\
\hline
\end{tabular}




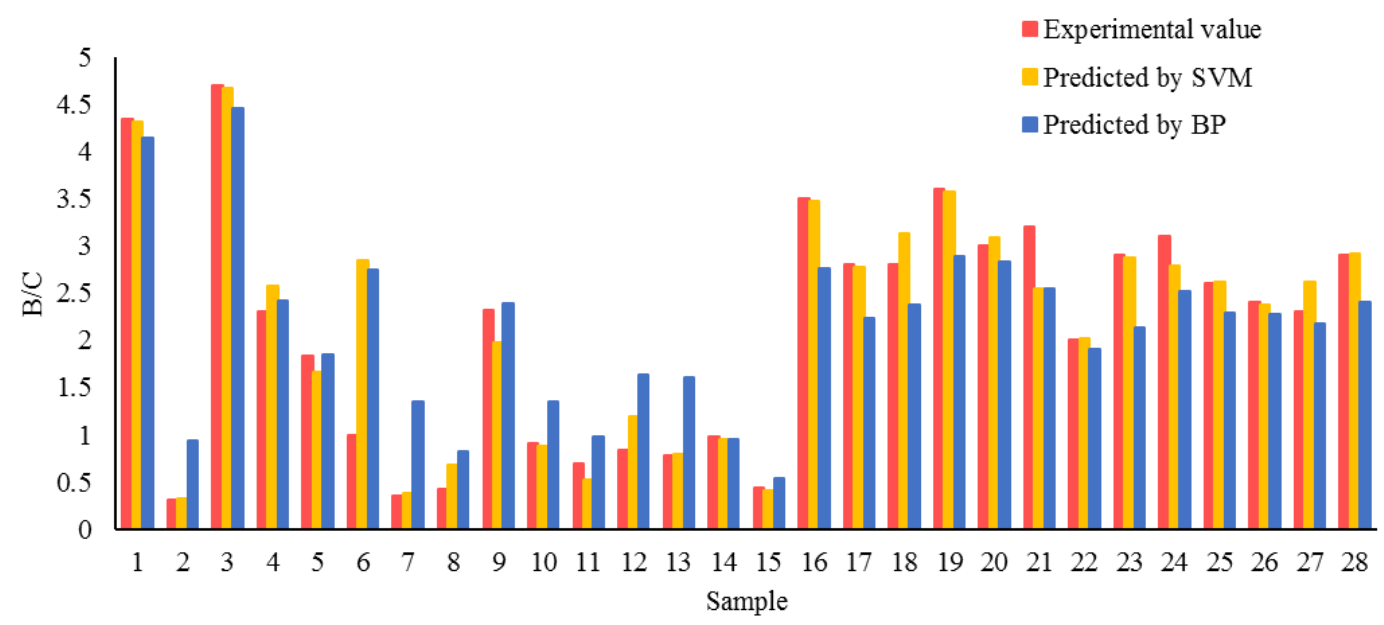

Fig 8. Predicted B/C without reactor scale (input variables are T, Q, P, ID, In_ $\mathrm{BCl}_{3}, \mathrm{In}_{-} \mathrm{CH}_{4}$, and In_ $\mathrm{H}_{2}$ )

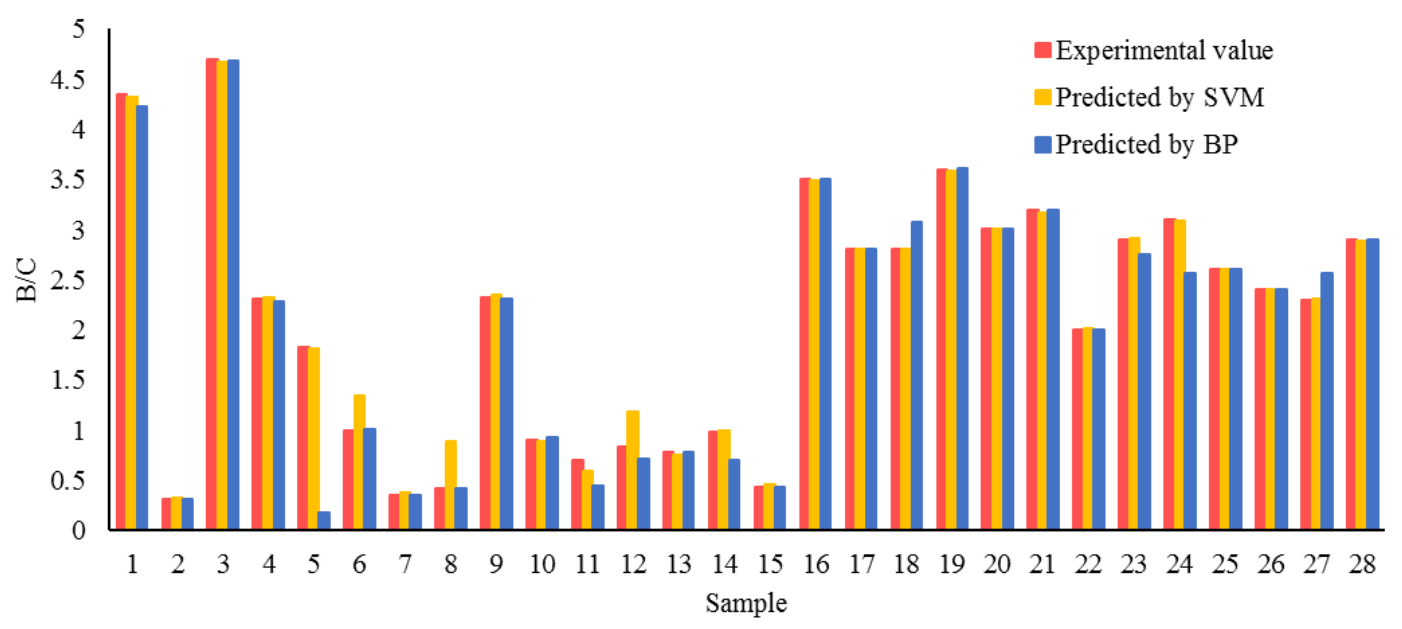

Fig 9. Predicted $\mathrm{B} / \mathrm{C}$ with reactor scale (Input variables are $\mathrm{T}, \mathrm{P}, \mathrm{BCl}_{3}, \mathrm{CH}_{4}, \mathrm{BHCl}_{2}, \mathrm{BHCl}_{3}, \mathrm{BCl}_{2}$, $\mathrm{HCl}$, and $\mathrm{H}_{2}$ ).

One important application of the ML approach is to interpolate the correlation of $\mathrm{B} / \mathrm{C}$ ratio vs. experimental control parameters. Given the fixed processing parameters, we calculate the $\mathrm{B} / \mathrm{C}$ ratio with temperature in Fig. 10. Our model predict that the $\mathrm{B} / \mathrm{C}$ ratio attain a minimum at $\sim 950^{\circ} \mathrm{C}$ and then increase to the maximum at $1100^{\circ} \mathrm{C}$. Liu et al. found that even at the same gas ratio, the atomic composition obtained at different 
deposition temperatures is different [15]. Liu and us both reach the same conclusion that it is not possible to simply establish a relationship between the gas ratio and the deposition result.

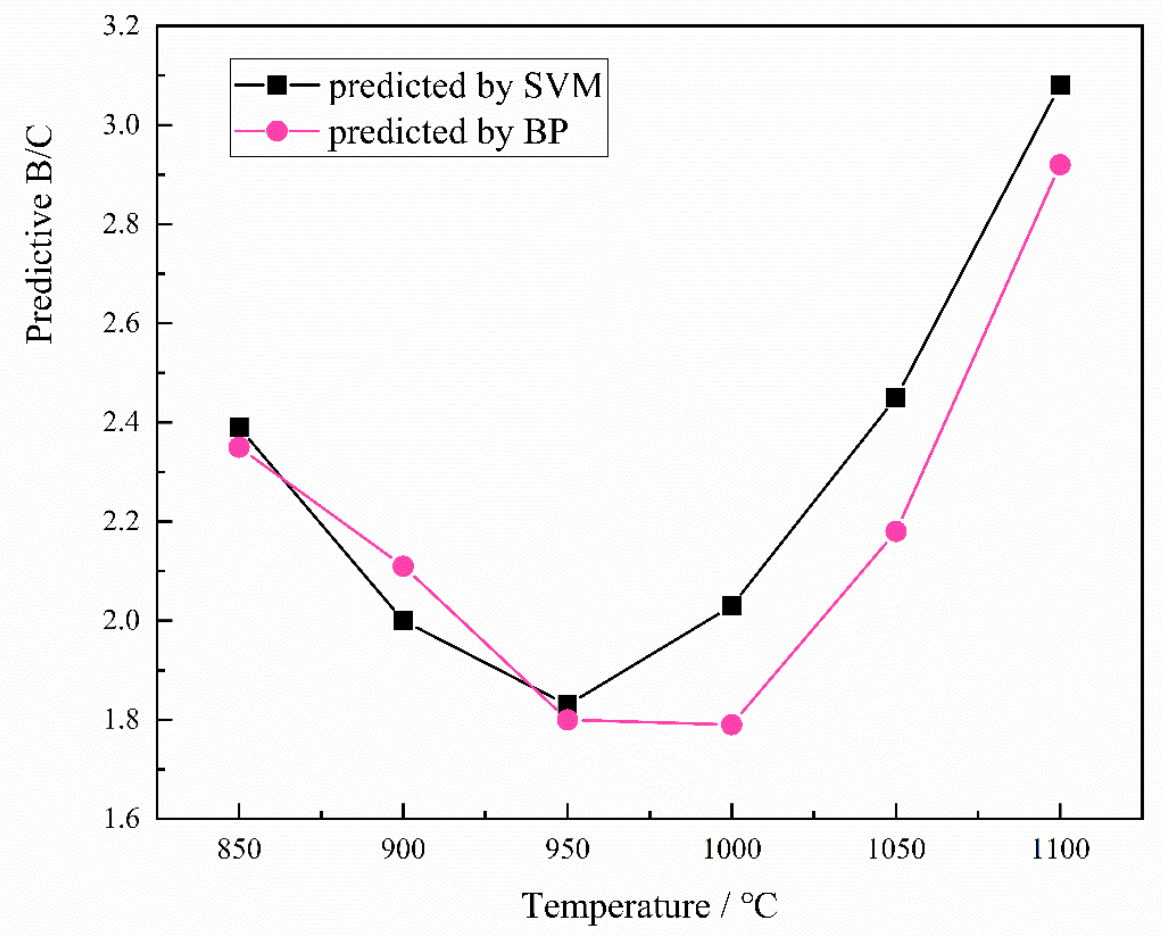

Fig 10. Plot of the $\mathrm{B} / \mathrm{C}$ ratios with deposition temperature, total pressure is $12 \mathrm{kPa}$, total gas flow rate is $210 \mathrm{sccm}, \mathrm{In}_{-} \mathrm{BCl}_{3}$ is $2 / 7$ and $\mathrm{In}_{-} \mathrm{CH}_{4}$ is $1 / 7$.

\subsection{Sensitivity coefficient analysis}

After the training session, sensitivity analysis was performed with SVM. Sensitivity coefficients were calculated with respect to the $\mathrm{B} / \mathrm{C}$ :

$$
\mathrm{S}(\mathrm{k})=\frac{v_{0}-v}{v}
$$

Here, $v_{0}$ is the predicted deposition B/C by SVM training model when the molar fraction of the $i$ th gas species is fixed as zero, and the concentrations of the other species 
remain unchanged; $v$ is the original deposition rate predicted by SVM training model. Therefore, "sensitivity" indicates the degree of influence on the predicted ratio of the components of the deposited product when the studied species is removed. Sensitivity analysis can be used to identify core species in a deposition mechanism. Obviously, a larger $\mathrm{S}(\mathrm{k})$ value for a certain substance indicates that it plays a dominant role in the deposition process.

Corresponding to $900{ }^{\circ} \mathrm{C}, 1000^{\circ} \mathrm{C}$, and $1100{ }^{\circ} \mathrm{C}$, we selected samples 2,7 , and 15 to study the sensitivity coefficient. The sensitivity analysis results (Fig. 11) showed that the intermediate species with molar fractions that limit the $\mathrm{B} / \mathrm{C}$ ratio are $\mathrm{BCl}_{3}, \mathrm{CH}_{4}$, $\mathrm{BHCl}_{2}, \mathrm{BHCl}_{3}, \mathrm{CH}_{3} \mathrm{BCl}_{2}, \mathrm{C}_{2} \mathrm{H}_{4}, \mathrm{C}_{2} \mathrm{H}_{2}, \mathrm{CH}_{4}, \mathrm{HCl}$, and $\mathrm{H}_{2}$. The sensitivity coefficients of other species were below 0.01 , which suggests they minimally influence the $B / C$ ratio. $\mathrm{BHCl}_{2}$ and $\mathrm{BCl}_{3}$ provide the most productivity for boron atoms, while $\mathrm{C}_{2} \mathrm{H}_{4}$ and $\mathrm{CH}_{4}$ are the main sources of carbon atoms. The sensitivity coefficient of $\mathrm{CH}_{4}$ was the largest, which is consistent with the deposition mechanism proposed by Vandenbulcke et al. [39]. Lartigue et al. also indicated that the production of $\mathrm{CH}_{4}$ is a predominant step toward deposition [40]. The intermediate $\mathrm{BHCl}_{2}$ was found to be very important to the deposition process, which is also consistent with Vandenbulcke's experimental results.

To compare with the effects of boron- and carbon-containing intermediate species on the composition of deposited products, the sensitivity coefficient of the main boronand carbon-containing intermediate species were separately calculated and then compared in Figure 12. The sensitivity coefficient of the boron-containing intermediate species increased with temperature. On the contrary, the sensitivity coefficients of carbon-containing intermediates were larger at $900^{\circ} \mathrm{C}$, and the values were higher than that of boron-containing species. This is consistent with the reported mechanism, which states that methane decomposes less as compared to boron trichloride at low temperature. This result is also consistent with the reported thermodynamic calculation results [38]. Therefore, the deposit composition is limited by methane at low temperature. At $1000{ }^{\circ} \mathrm{C}$ and $1100{ }^{\circ} \mathrm{C}$, the decomposition of the boron- and carbon- 
containing intermediate species were similar, which demonstrate a competitive deposition mechanism. Thus co-deposition occurs, and the $\mathrm{B} / \mathrm{C}$ ratio of the deposits gradually decreased with temperature. We concluded the main factor controlling the boron-carbon ratio is temperature. Methane is the controlling gas species of the deposit compositions at low temperatures $\left(\sim 900^{\circ} \mathrm{C}\right)$, while methane and boron trichloride both affect the deposit compositions at higher temperatures $\left(>900{ }^{\circ} \mathrm{C}\right)$.

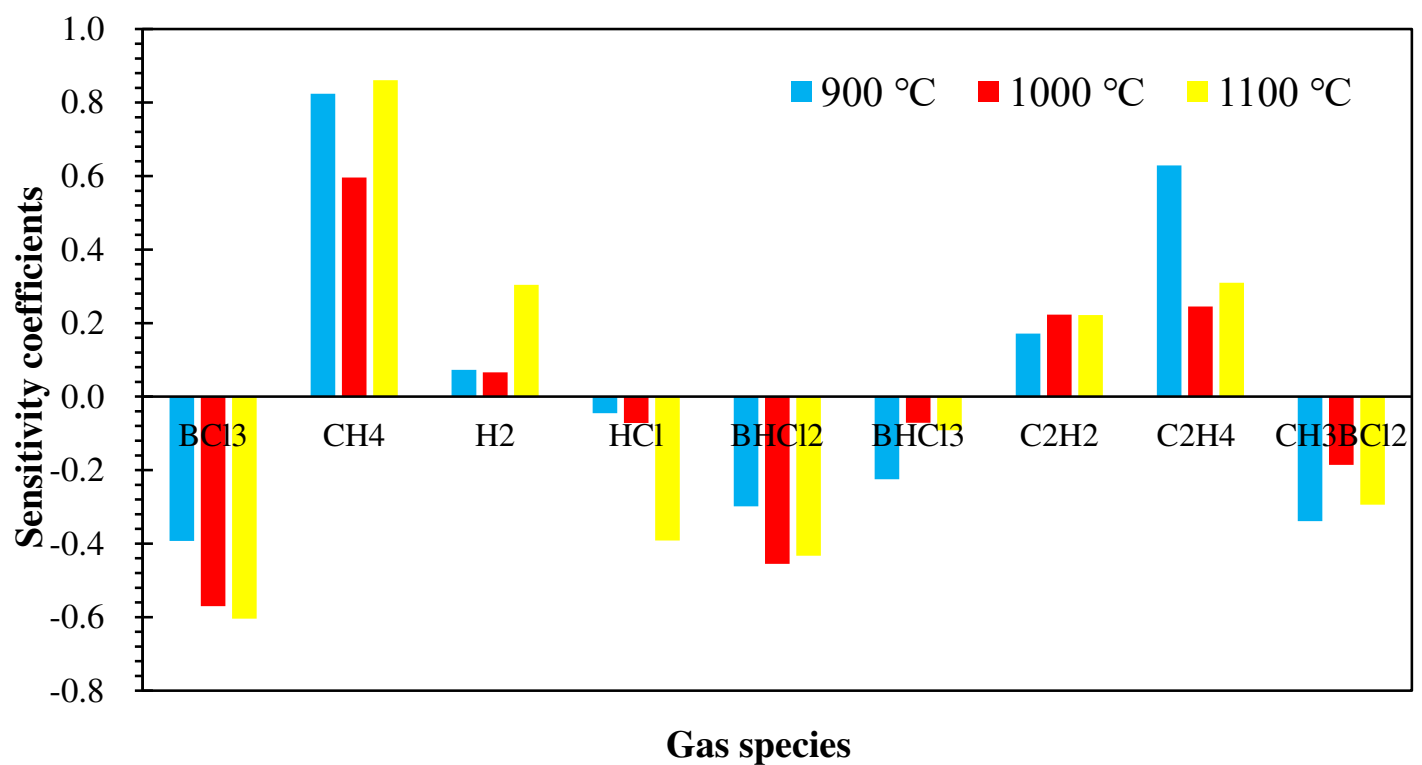

Fig 11. Analysis of the sensitivity of the intermediate species with respect to the $\mathrm{B} / \mathrm{C}$ under different temperatures by ML.

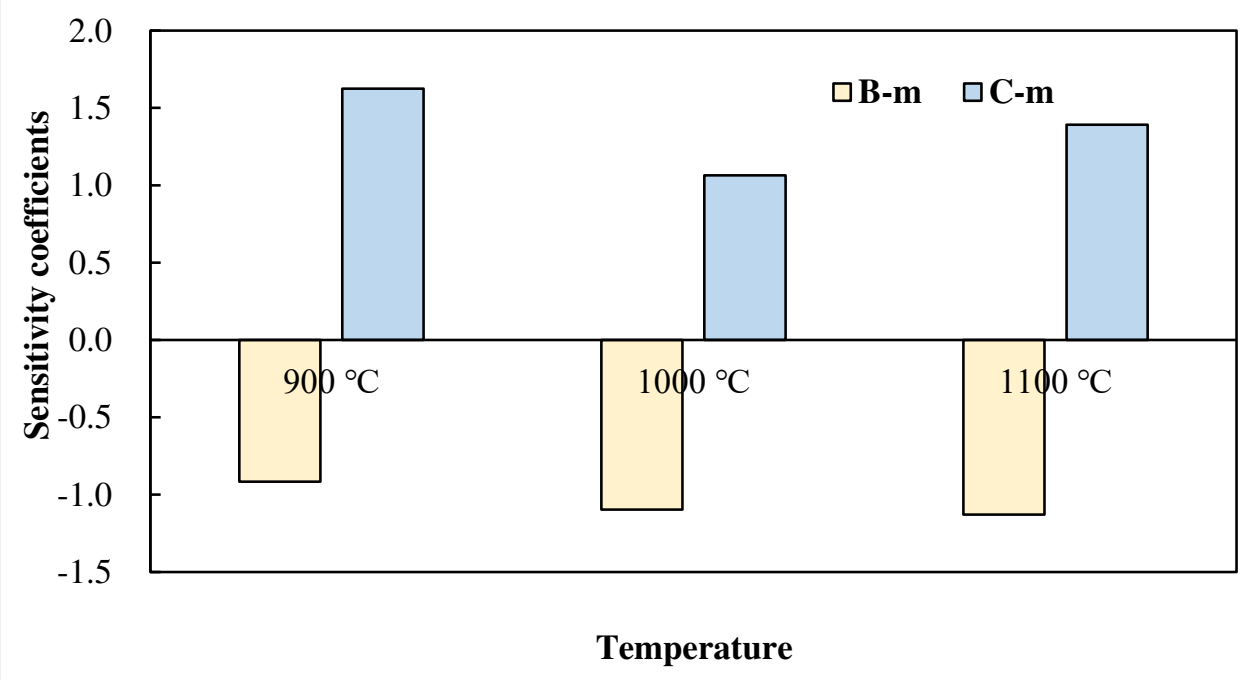


Fig 12 . Analysis of the sensitivity coefficient of the main intermediate gas species containing boron (B-m) and containing carbon (C-m) at different temperatures.

\section{Conclusion}

(1) Based on the reported experimental results, we established a simplified twodimensional reactor model, which couples gas-phase reaction, as well as heat and mass transfer, for a $\mathrm{BCl}_{3}-\mathrm{CH}_{4}-\mathrm{H}_{2}$ system.

(2) The main intermediate species were $\mathrm{BCl}_{3}, \mathrm{CH}_{4}, \mathrm{BHCl}_{2}, \mathrm{BHCl}_{3}, \mathrm{CH}_{3} \mathrm{BCl}_{2}, \mathrm{C}_{2} \mathrm{H}_{4}$, $\mathrm{C}_{2} \mathrm{H}_{2}, \mathrm{CH}_{4}, \mathrm{HCl}$, and $\mathrm{H}_{2}$, and the changes in $\mathrm{BHCl}_{2}$ and $\mathrm{HCl}$ were the same. This result was consistent with the main reaction $\mathrm{BCl}_{3}+\mathrm{H}_{2} \rightarrow \mathrm{HBCl}_{2}+\mathrm{HCl}$.

(3) Comparing machine learning techniques without reactor-scale model, the prediction error of machine learning techniques incorporated with reactor-scale model was reduced from $25 \%$ to $7 \%$.

(4) Sensitivity analysis shows that, with the exception of temperature, $\mathrm{CH}_{4}$ is the key factor in controlling the deposit compositions at low temperature, while $\mathrm{CH}_{4}$ and $\mathrm{BCl}_{3}$ are both important at high temperature.

In summary, the combination of reactor model and machine learning allows for the prediction of the boron-carbon ratio of the deposited product within a reasonable error range (less than 10\%). This method can also be applied to other multi-element CVD systems.

\section{Acknowledgement}

We thank the National Key R\&D Program of China (Grants No. 2017YFB0703200), National Natural Science Foundation of China (Grants No. 51702100, 51972268) and China Postdoctoral Science Foundation (Grants No. 2018M643075) for financial support. 


\section{References}

[1] Ohnabe H, Masaki S, Onozuka M, et al. Potential Application of Ceramic Matrix Composites to Aero-Engine Components. Compos Part A-Appl S 1999, 30: 489-96.

[2] Inghels $\mathrm{E}$, Lamon $\mathrm{J}$. An approach to the mechanical behaviour of $\mathrm{SiC} / \mathrm{SiC}$ and $\mathrm{C} / \mathrm{SiC}$ ceramic matrix composites. J Mater Sci 1991, 26: 5411-9.

[3] Christin F. Design, fabrication, and application of thermostructural composites (TSC) like C/C, C/SiC, and $\mathrm{SiC} / \mathrm{SiC}$ composites. Adv Eng Mater 2002, 4: 903-12.

[4] Katoh Y, Snead LL, Henager CH, et al. Current status and recent research achievements in SiC/SiC composites. J Nucl Mater 2014, 455: 387-97.

[5] Naslain R, Guette A, Rebillat F, et al. Boron-bearing species in ceramic matrix composites for long-term aerospace applications. J Solid State Chem 2004, 30: 489-96.

[6] Liu YS, Cheng LF, Zhang LT, et al. Oxidation protection of multilayer CVD SiC/B/SiC coatings for 3D C/SiC composite. Mat Sci Eng A-Struct 2007 466: 172-7.

[7] Sezer AO, Brand JI. Chemical vapor deposition of boron carbide. Mater Sci Eng B-Adv 2001 79: $191-202$.

[8] Jacques S, Guette A, Langlais F, et al. C(B) materials as interphases in $\mathrm{SiC} / \mathrm{SiC}$ model microcomposites. J Mater Sci 1997.

[9] Ruggles-Wrenn MB, Wallis TA. Creep in interlaminar shear of an Hi-Nicalon ${ }^{\mathrm{TM}} / \mathrm{SiC}^{-} \mathrm{B}_{4} \mathrm{C}$ composite at $1300^{\circ} \mathrm{C}$ in air and in steam. J Compos Mater 2019, 54: 1819-29.

[10] Deshpande SV, Gulari E, Harris SJ, et al. Filament activated chemical vapor deposition of boron carbide coatings. Appl Phys Lett 1994, 65: 1757-9.

[11] Karaman M, Sezgi NA, Doğu T, et al. Kinetic investigation of chemical vapor deposition of $\mathrm{B}_{4} \mathrm{C}$ on tungsten substrate. AICHE $J$ 2006, 52: 4161-6.

[12] Karaman M, Sezgi NA, Doğu T, et al. Mechanism studies on CVD of boron carbide from a gas mixture of $\mathrm{BCl}_{3}, \mathrm{CH}_{4}$, and $\mathrm{H}_{2}$ in a dual impinging-jet reactor. AICHE J 2009, 55: 701-9.

[13] Berjonneau J, Langlais $\mathrm{F}$, Chollon $\mathrm{G}$, et al. Understanding the CVD process of ( $\mathrm{Si}$ )-B-C ceramics through FTIR spectroscopy gas phase analysis. Surf Coat Tech 2017, 201: 7273-85.

[14] Berjonneau J, Chollon G, Langlais F, et al. Deposition process of $\mathrm{Si}-\mathrm{B}-\mathrm{C}$ ceramics from $\mathrm{CH}_{3} \mathrm{SiCl}_{3} / \mathrm{BCl}_{3} / \mathrm{H}_{2}$ precursor. Thin Solid Films 2008, 516: 2848-57. 
[15] Liu YS, Zhang LT, Cheng LF, et al. Uniform design and regression analysis of LPCVD boron carbide from $\mathrm{BCl}_{3}-\mathrm{CH}_{4}-\mathrm{H}_{2}$ system. Appl Surf Sci 2009, 255: 5729-35.

[16] Zeng B, Feng ZD, Li SW, et al. Microstructural study of oxidation of carbon-rich amorphous boron carbide coating. Front Mater Sci 2008, 2: 375-80.

[17] Mollick PK, Venugopalan R, Srivastava D. CFD coupled kinetic modeling and simulation of hot wall vertical tubular reactor for deposition of SiC crystal from MTS. J Cryst Growth 2017, 475: 97-109.

[18] Ni H, Lu S, Chen C. Modeling and simulation of silicon epitaxial growth in siemens cvd reactor. J Cryst Growth 2014, 404: 89-99.

[19] Deck CP, Khalifa HE, Sammuli B, et al. Fabrication of SiC-SiC composites for fuel cladding in advanced reactor designs. Prog Nucl Energy 2012, 57: 38-45.

[20] Reinisch G, Patel S, Chollon G, et al. Methyldichloroborane evidenced as an intermediate in the chemical vapour deposition synthesis of boron carbide. J Nano Nanotechnol 2011, 11:8323-8327.

[21] Li J, Qin H, Liu Y, et al. Effect of the $\mathrm{SiCl}_{4}$ flow rate on $\mathrm{SiBN}$ deposition kinetics in $\mathrm{SiCl}_{4}$ $\mathrm{BCl}_{3}-\mathrm{NH}_{3}-\mathrm{H}_{2}-\mathrm{Ar}$ environment. Materials 2017, 10: 627.

[22] Kleijn C R . Modeling of chemical vapor deposition of tungsten films. Birkhäuser Basel 1993.

[23] Beek W J , Muttzall K M K, Heuven J W V . Transmission phenomenon. Chemical Industry Press 2003.

[24] Cuadros F, Cachadiña I, Ahumada W. Determination of Lennard-Jones interaction parameters using a new procedure. Mol Eng 1996, 6: 319-25.

[25] Ge Y, Gordon M S, Battaglia F, et al. Theoretical study of the pyrolysis of methyltrichlorosilane in the gas phase. 1. Thermodynamics. J Phys Chem A 2007, 111: 146274.

[26] Ge Y, Gordon M S, Battaglia F, et al. Theoretical study of the pyrolysis of methyltrichlorosilane in the gas phase. 2. Reaction paths and transition states. $J$ Phys Chem A 2007,111: 1475-86.

[27] Ge Y, Gordon M S, Battaglia F, et al. Theoretical study of the pyrolysis of methyltrichlorosilane in the gas phase. 3.Reaction Rate Constant Calculations. J Phys Chem A 2010, 114: 2384-92.

[28] Yan L, Su K, Zeng Q, et al. Reaction paths of $\mathrm{BCl}_{3}+\mathrm{CH}_{4}+\mathrm{H}_{2}$ in the chemical vapor deposition process. Struct Chem 2012, 23.

[29] Liu Y, Su K, Zeng Q, et al. Decomposition reaction rate of $\mathrm{BCl}_{3}-\mathrm{CH}_{4}-\mathrm{H}_{2}$ in the gas phase. Theor Chem Acc 2015, 134. 
[30] Reinisch G, Leyssale J M, Vignoles G L. Theoretical study of the decomposition of $\mathrm{BCl}_{3}$ induced by a $\mathrm{H}$ radical. $J$ Phys Chem A 2011, 115: 4786-97.

[31] Lee J H, Shin J, Realff M J. Machine learning: Overview of the recent progresses and implications for the process systems engineering field. Comput Chem Eng 2018, 114: 111-21.

[32] Moreno R, Corona F, Lendasse A, et al. Extreme learning machines for soybean classification in remote sensing hyperspectral images. Neurocomputing 2014, 128: 207-16.

[33] Basu A, Shuo S, Zhou H, et al. Silicon spiking neurons for hardware implementation of extreme learning machines. Neurocomputing 2013, 102: 125-34.

[34] Benoît F, Heeswijk M, Miche Y, et al, Feature selection for nonlinear models with extreme learning machines. Neurocomputing 2013, 102: 111-24.

[35] Feng S, Zhou H, Dong H, et al. Using deep neural network with small dataset to predict material defects. Mater Des 2019, 162: 300-10.

[36] Kushvaha V, Kumar S A, Madhushri P, et al. Artificial neural network technique to predict dynamic fracture of particulate composite. J Compos Mater 2020.

[37] Liu X, Gao C, Li P, et al. A comparative analysis of support vector machines and extreme learning machines. Neural Netw 2012, 33: 58-66.

[38] Berjonneau J, Chollon G, Langlais F, et al. Deposition process of amorphous boron carbide from $\mathrm{CH}_{4} / \mathrm{BCl}_{3} / \mathrm{H}_{2}$ precursor. Proceedings Electrochemical Society 2006, 153: C795-C800.

[39] Vandenbulcke L G. Theoretical and experimental studies on the chemical vapor deposition of boron carbide. Ind Eng Chem Res 2002, 24: 568-75.

[40] Lartigue S, Cazajous D, Nadal M, et al. Study of boron carbides vapor-deposited under low pressure. In: In proceedings of the fifth European conference on chemical vapor deposition. Uppsala. Sweden: Uppsala University, Department of Chemistry. 1985: 413-9. 
Figures

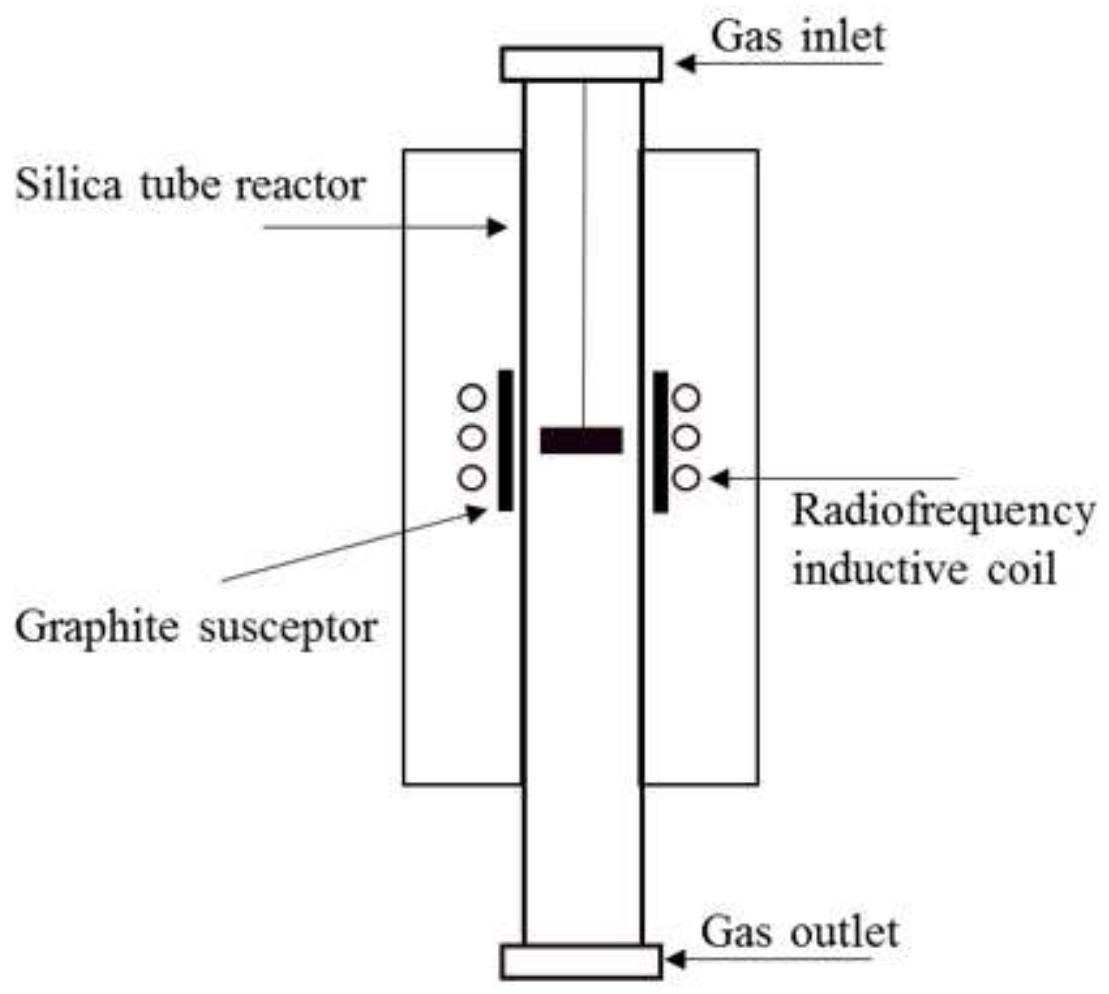

Figure 1

CVD reactor equipment diagram.

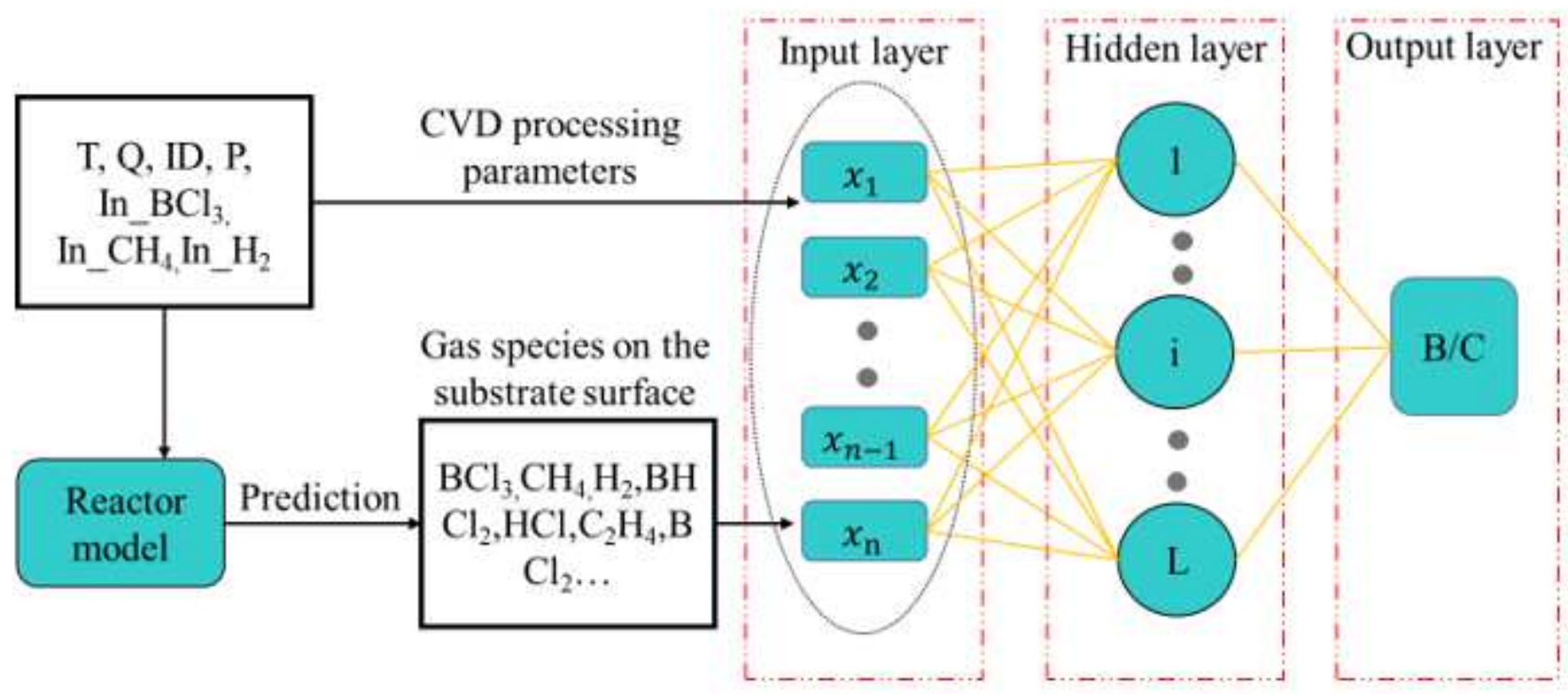

Figure 2

$\mathrm{ML}$ model design for $\mathrm{B} / \mathrm{C}$ prediction. 


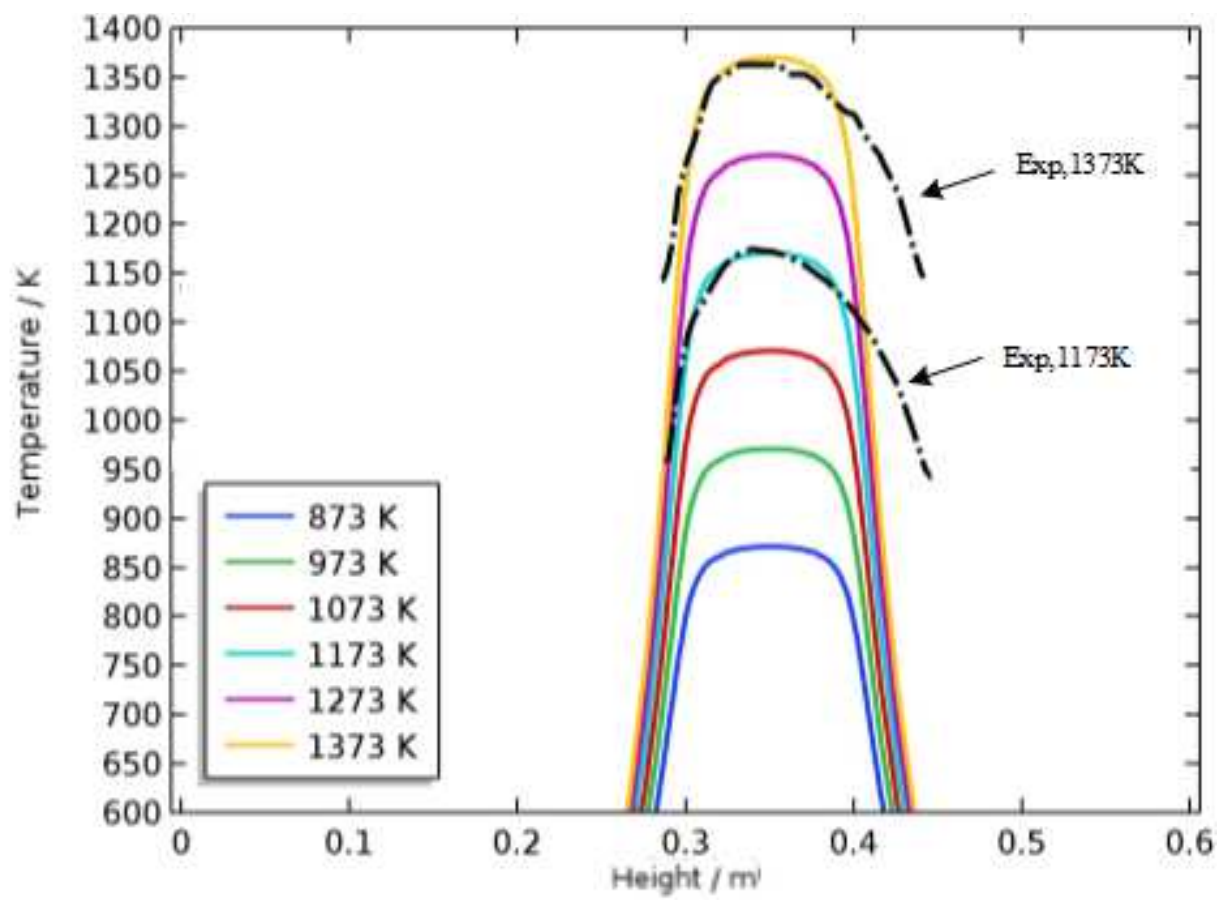

Figure 3

Axial temperature distribution curve in the reactor at different deposition temperatures. 

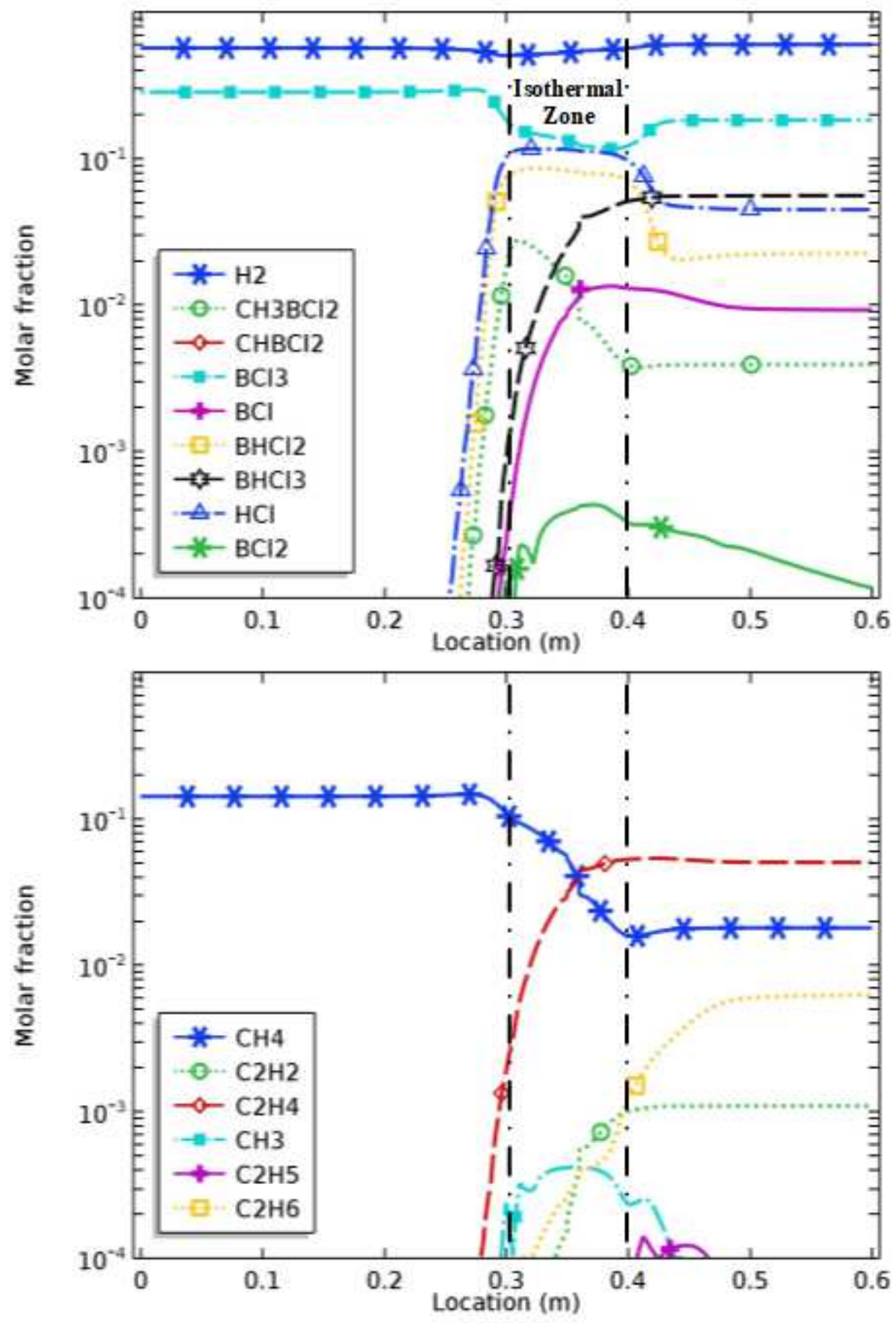

Figure 4

Plot of the gas-phase compositions along the reactor height: for deposition temperature of $1000^{\circ} \mathrm{C}$, total pressure of $12 \mathrm{kPa}$, total gas flow rate of $210 \mathrm{sccm}$, In_BCl3 is 2/7 and In_CH4 is 1/7. 


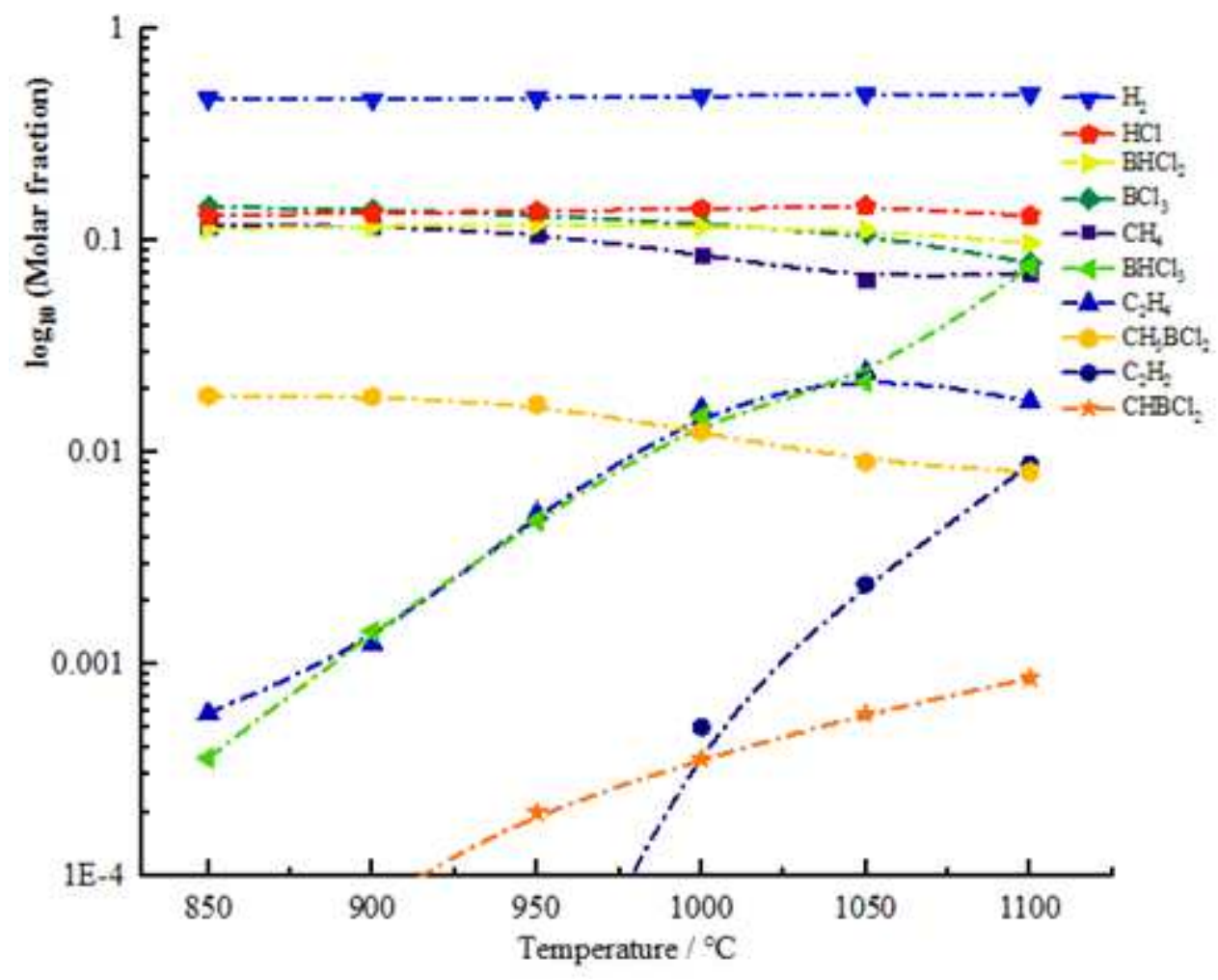

Figure 5

Influence of temperature on the mole fraction of intermediate components. total pressure of $12 \mathrm{kPa}$, total gas flow rate of $210 \mathrm{sccm}$, In_BCl3 is $2 / 7$ and In_CH4 is $1 / 7$.

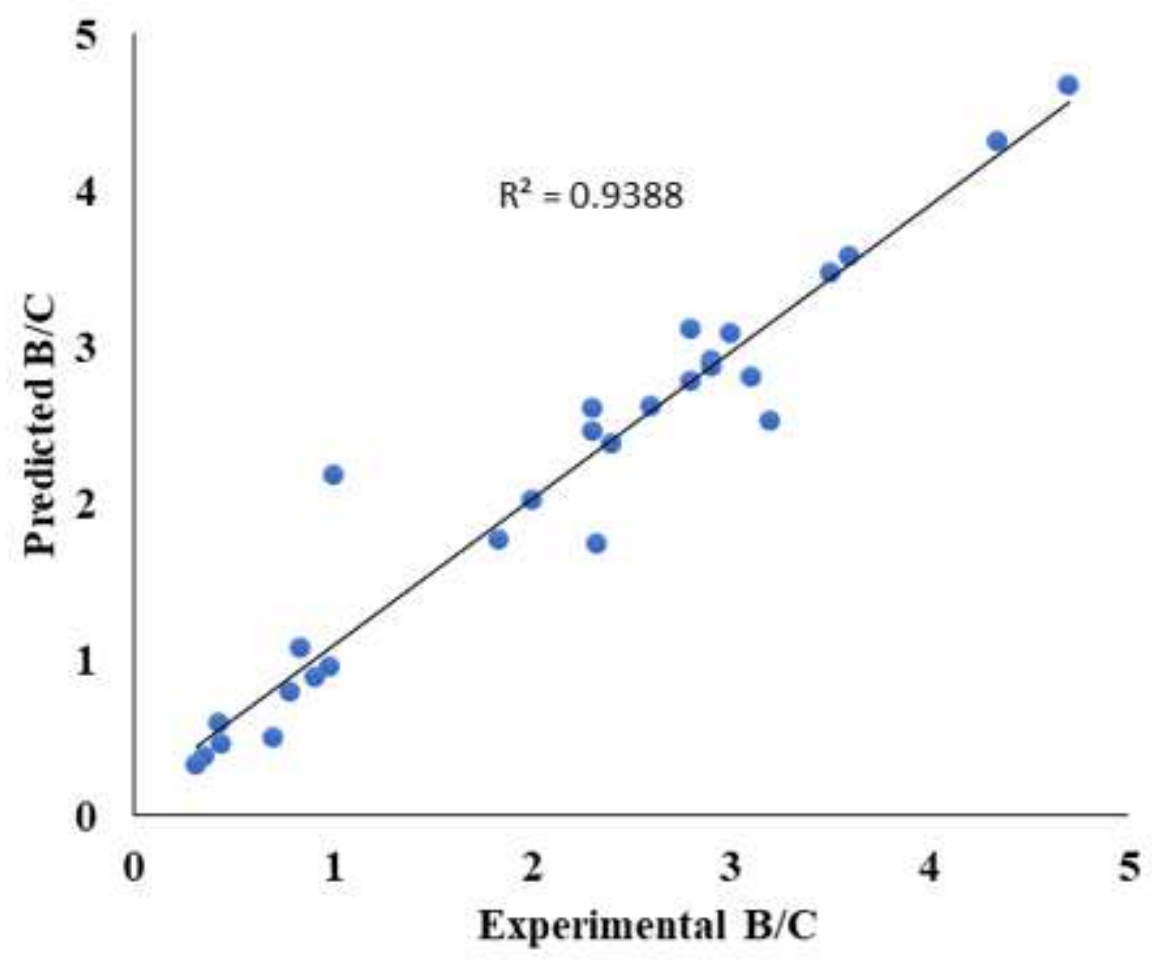

Figure 6 
Goodness of fit (input variables are T, Q, P, In_BCl3, In_CH4, and In_H2).

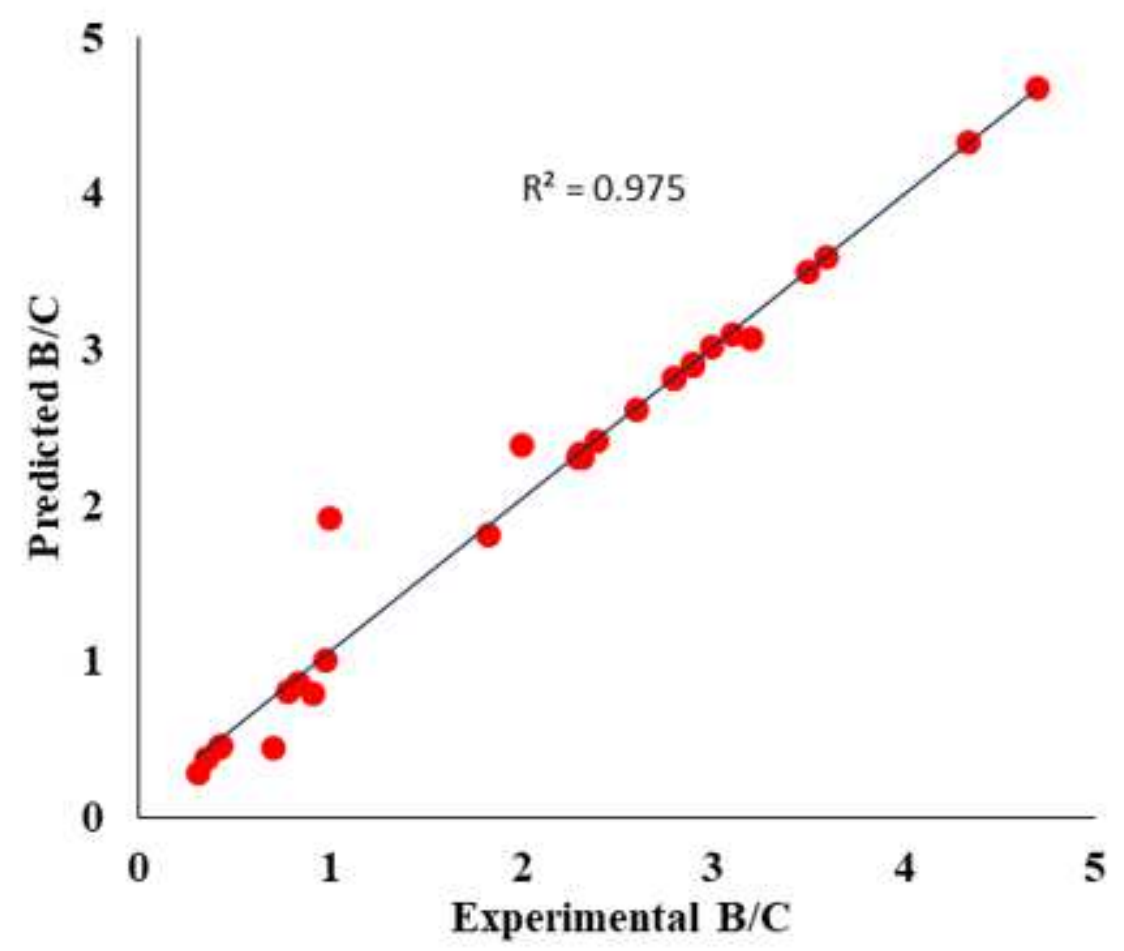

Figure 7

Goodness of fit (input variables are $\mathrm{T}, \mathrm{P}, \mathrm{BCl} 3, \mathrm{CH} 4, \mathrm{BHCl} 2, \mathrm{BHCl} 3, \mathrm{BCl} 2, \mathrm{HCl}$, and $\mathrm{H} 2$ ).

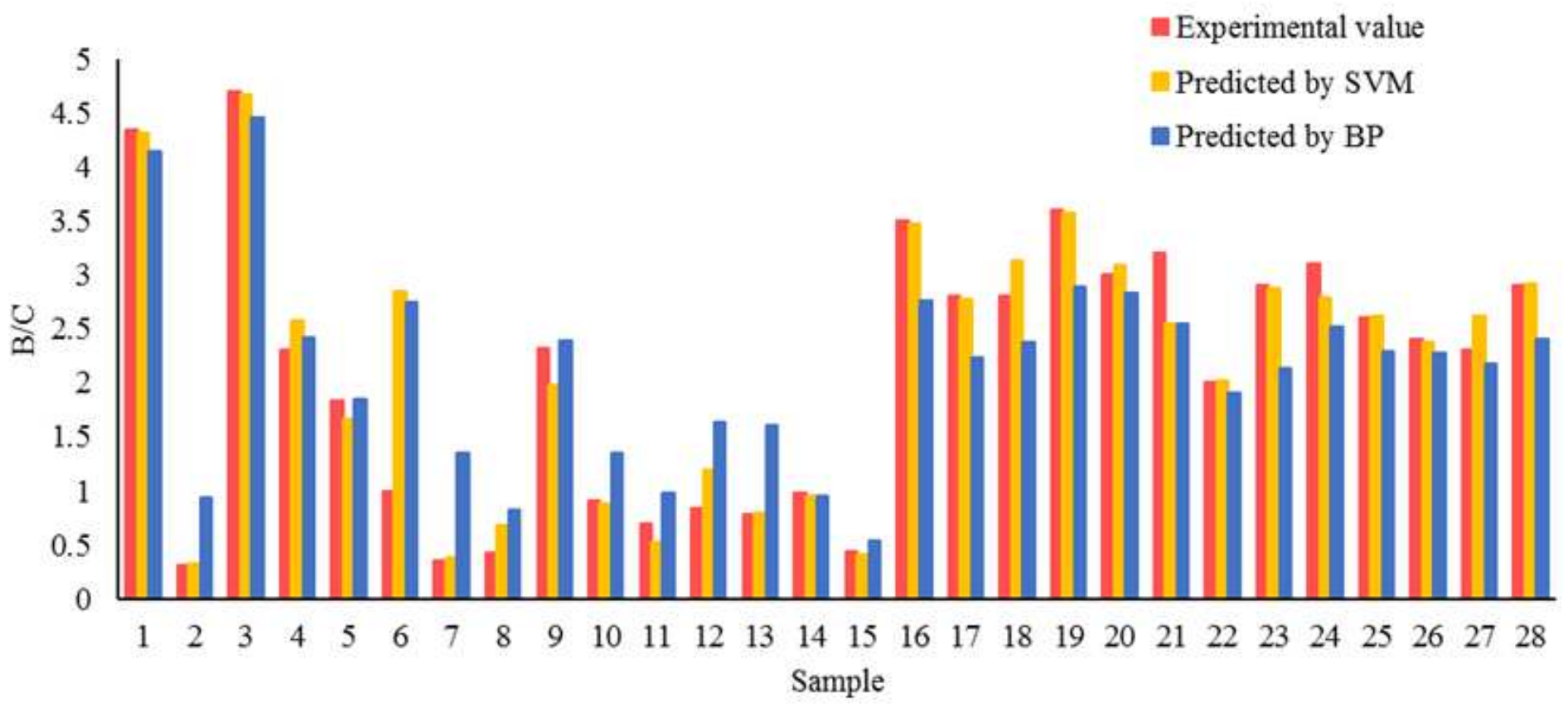

Figure 8

Predicted B/C without reactor scale (input variables are T, Q, P, ID, In_BCl3, In_CH4, and In_H2) 


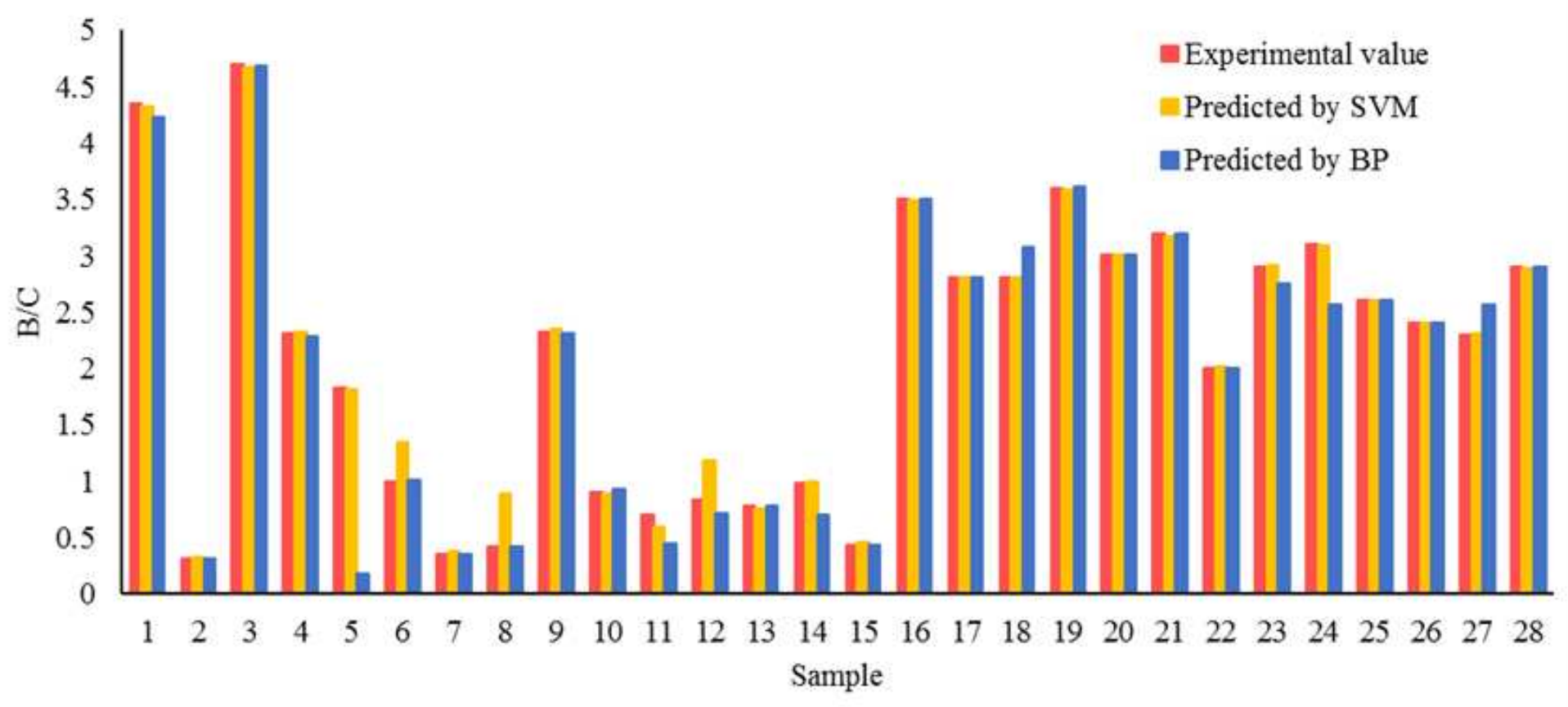

Figure 9

Predicted $\mathrm{B} / \mathrm{C}$ with reactor scale (Input variables are $\mathrm{T}, \mathrm{P}, \mathrm{BCl} 3, \mathrm{CH} 4, \mathrm{BHCl} 2, \mathrm{BHCl} 3, \mathrm{BCl} 2, \mathrm{HCl}$, and $\mathrm{H} 2$ ).

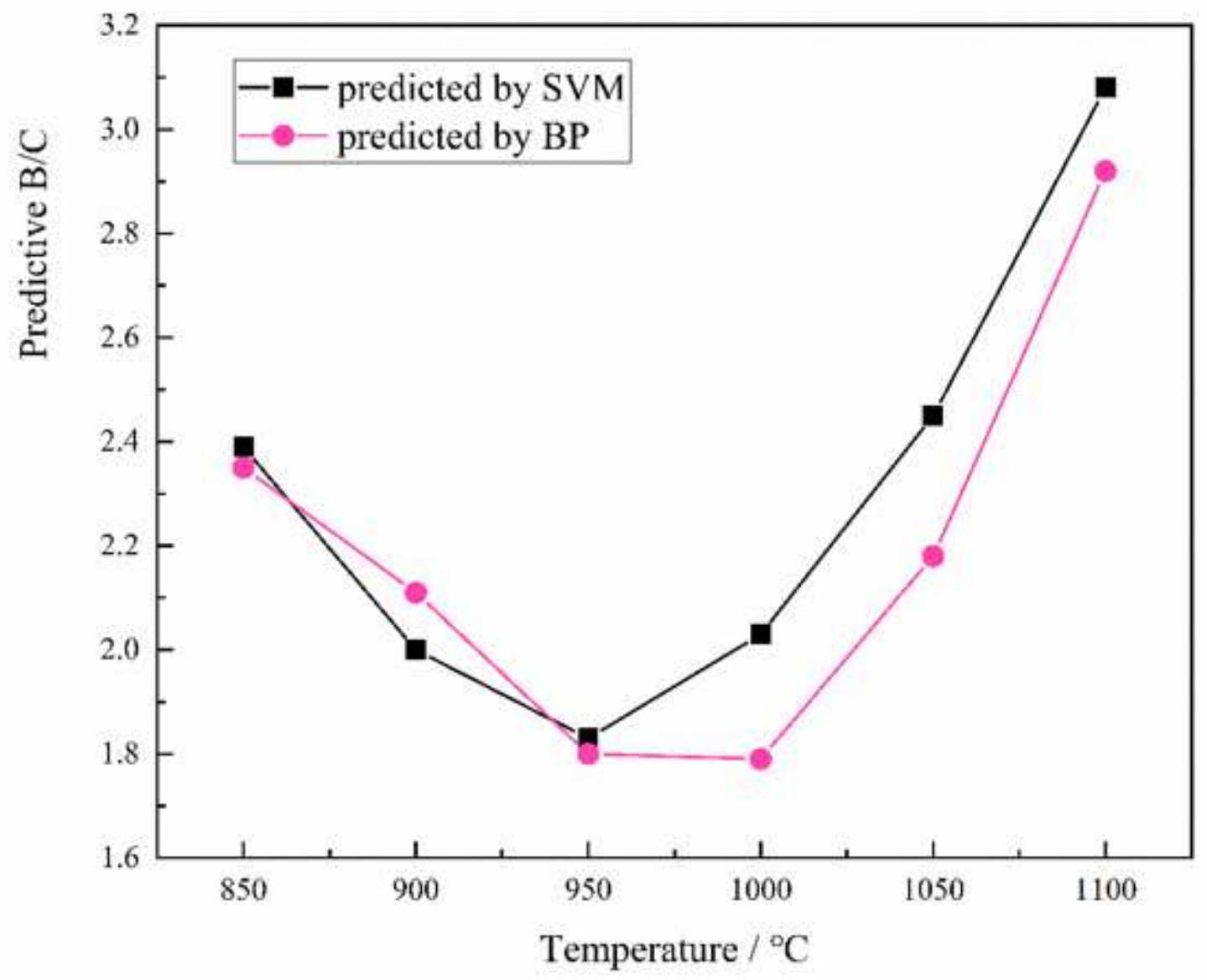

Figure 10 
Plot of the $\mathrm{B} / \mathrm{C}$ ratios with deposition temperature, total pressure is $12 \mathrm{kPa}$, total gas flow rate is 210 sccm, In_BCl3 is $2 / 7$ and In_CH4 is $1 / 7$.

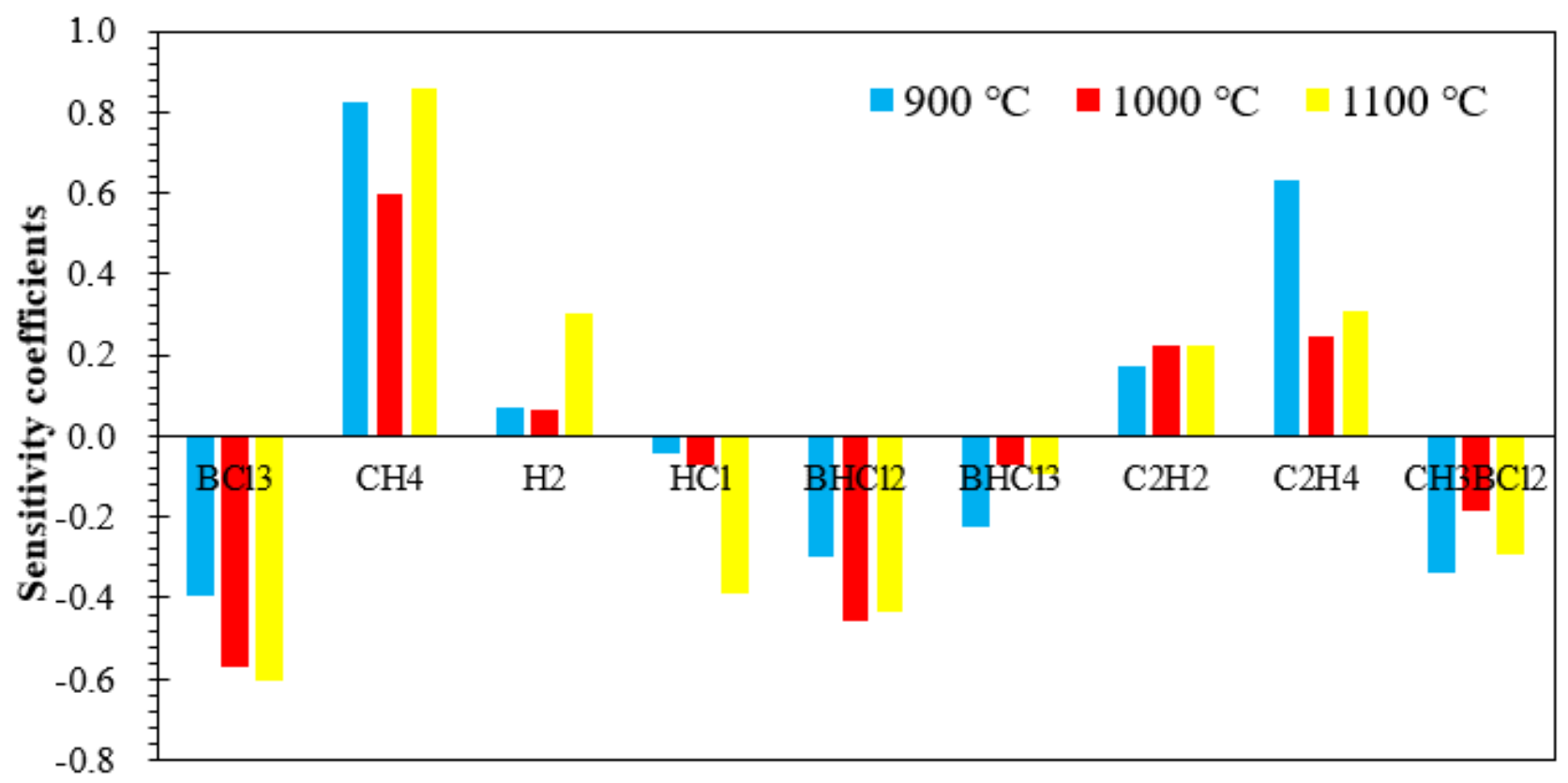

Gas species

Figure 11

Analysis of the sensitivity of the intermediate species with respect to the $B / C$ under different temperatures by ML.

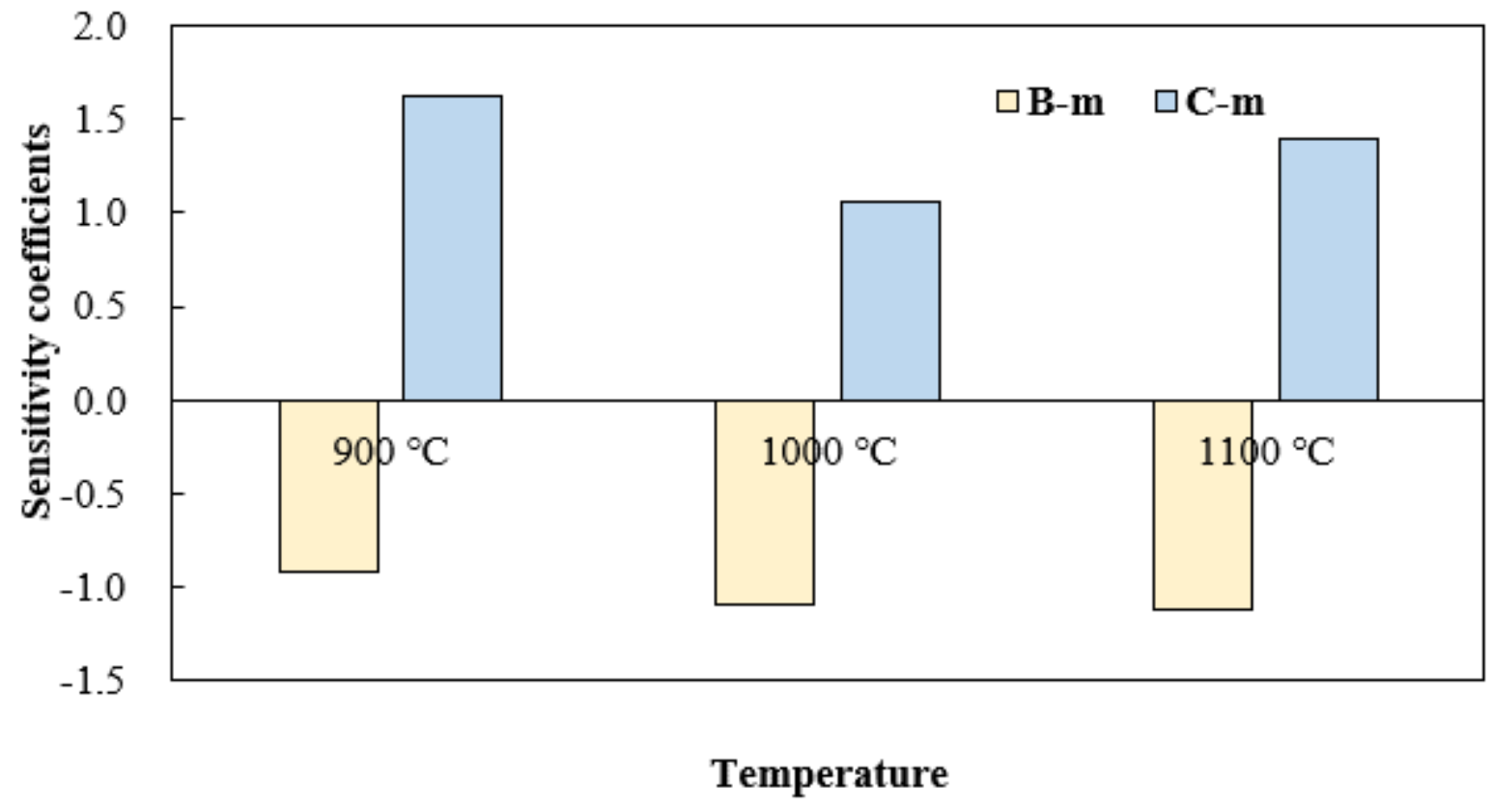

Figure 12 
Analysis of the sensitivity coefficient of the main intermediate gas species containing boron (B-m) and containing carbon (C-m) at different temperatures. 